\title{
Müller glia cells regulate Notch signaling and retinal angiogenesis via the generation of 19,20-dihydroxydocosapentaenoic acid
}

\author{
Jiong Hu, ${ }^{1}$ Rüdiger Popp, ${ }^{1}$ Timo Frömel, ${ }^{1}$ Manuel Ehling, ${ }^{2,3}$ Khader Awwad, ${ }^{1}$ \\ Ralf H. Adams, ${ }^{2,3}$ Hans-Peter Hammes, ${ }^{4}$ and Ingrid Fleming ${ }^{1}$ \\ IInstitute for Vascular Signaling, Centre for Molecular Medicine, Johann Wolfgang Goethe University and DZHK \\ (German Centre for Cardiovascular Research) partner site Rhine-Main, 60590 Frankfurt, Germany \\ 2Department of Tissue Morphogenesis, Max Planck Institute for Molecular Biomedicine, 48149 Münster, Germany \\ ${ }^{3}$ Faculty of Medicine, University of Münster, 48149 Münster, Germany \\ ${ }^{4}$ Fifth Medical Department, University Medicine Mannheim, University of Heidelberg, 68167 Mannheim, Germany
}

Cytochrome P450 (CYP) epoxygenases generate bioactive lipid epoxides which can be further metabolized to supposedly less active diols by the soluble epoxide hydrolase (sEH). As the role of epoxides and diols in angiogenesis is unclear, we compared retinal vasculature development in wild-type and $\mathrm{sEH}^{-l-}$ mice. Deletion of the $\mathrm{sEH}$ significantly delayed angiogenesis, tip cell, and filopodia formation, a phenomenon associated with activation of the Notch signaling pathway. In the retina, sEH was localized in Müller glia cells, and Müller cell-specific sEH deletion reproduced the $\mathrm{SEH}^{-/-}$retinal phenotype. Lipid profiling revealed that $\mathrm{sEH}$ deletion decreased retinal and Müller cell levels of 19,20-dihydroxydocosapentaenoic acid (DHDP), a diol of docosahexenoic acid (DHA). 19,20-DHDP suppressed endothelial Notch signaling in vitro via inhibition of the $\gamma$-secretase and the redistribution of presenilin 1 from lipid rafts. Moreover, 19,20-DHDP, but not the parent epoxide, was able to rescue the defective angiogenesis in $\mathrm{SEH}^{-/-}$mice as well as in animals lacking the Fbxw7 ubiquitin ligase, which demonstrate strong basal activity of the Notch signaling cascade. These studies demonstrate that retinal angiogenesis is regulated by a novel form of neuroretina-vascular interaction involving the $\mathrm{SEH}-$ dependent generation of a diol of DHA in Müller cells.

Cytochrome P450 (CYP) enzymes are involved in numerous detoxification and synthetic processes in addition to generating potent lipid mediators from endogenous substrates. Even though many CYP isozymes can oxidize a spectrum of $\omega-6$ and $\omega-3$ polyunsaturated fatty acids such as retinoic acid, linoleic acid, eicosapentaenoic acid (EPA), and docosahexenoic acid (DHA), they are often referred to as the third pathway of arachidonic acid metabolism, mainly because the most is known about the biological actions of these products (Konkel and Schunck, 2011).

Angiogenesis is a tightly regulated and organized process, and although numerous studies have addressed the role of specific proteins at the different stages of vascular development (Potente et al., 2011), the role of lipids is less clear. Although cyclooxygenases and prostaglandins have been the focus of some studies (Salvado et al., 2012), little is known about the role of CYP-derived lipid mediators. The first link between CYP enzymes and angiogenesis was obtained in co-cultures of astrocytes and endothelial cells in which arachidonic acid epoxides (epoxyeicosatrienoic acids [EETs]) released from astrocytes increased endothelial cell proliferation and elicited the formation of capillary-like structures (Munzenmaier and Harder, 2000; Zhang and Harder, 2002). Also, the overexpression of the CYP2C9 epoxygenase in, and/or the application of 11,12- or 14,15-EET to monocultures of endothelial cells was associated with angiogenesis (Medhora et al., 2003; Michaelis et al., 2003). In vivo data rapidly followed to support these in vitro findings, with

2014 Hu et al. This article is distributed under the terms of an AttributionNoncommercial-Share Alike-No Mirror Sites license for the first six months after the publication date (see http://www.rupress.org/terms). After six months it is available under a Creative Commons License (Attribution-NoncommercialShare Alike 3.0 Unported license, as described at http://creativecommons.org/ licenses/by-nc-sa/3.0/) 

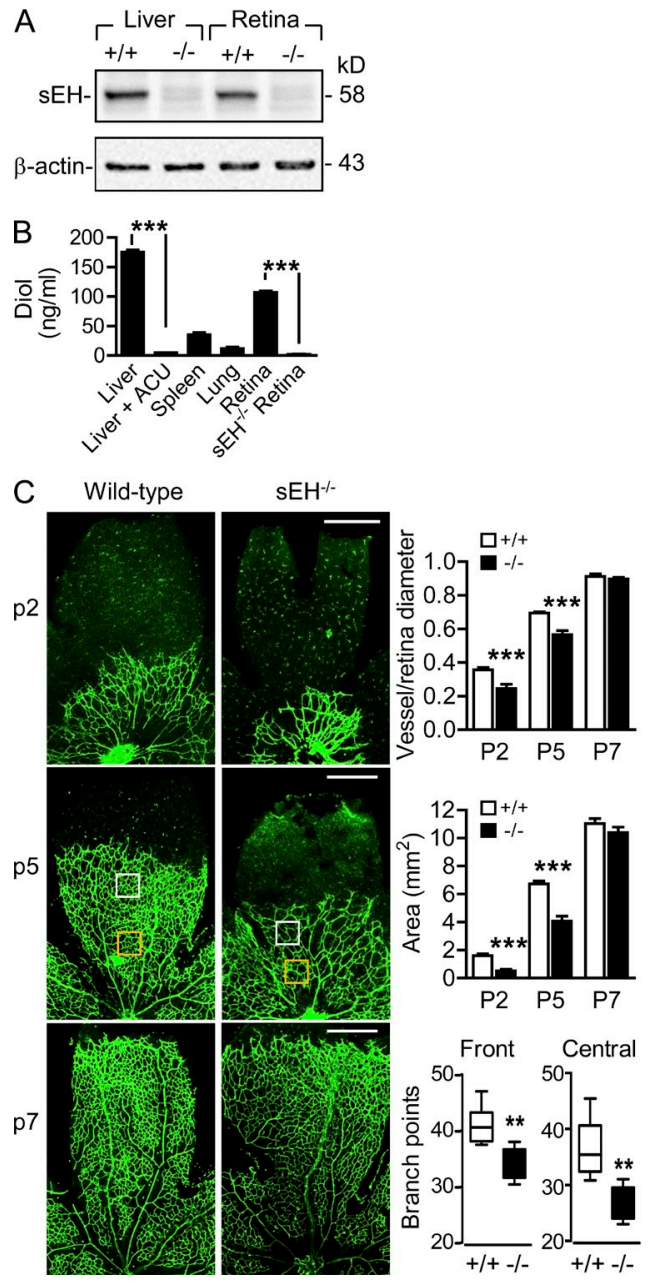
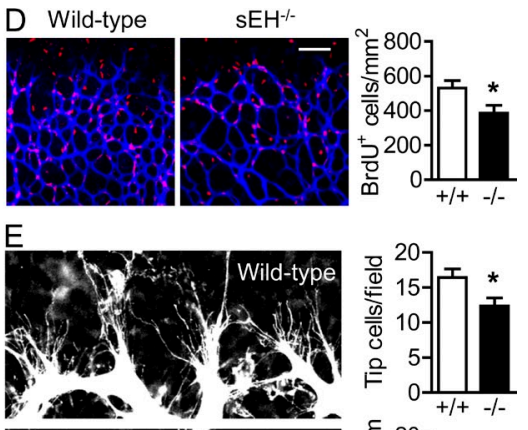

Wild-type
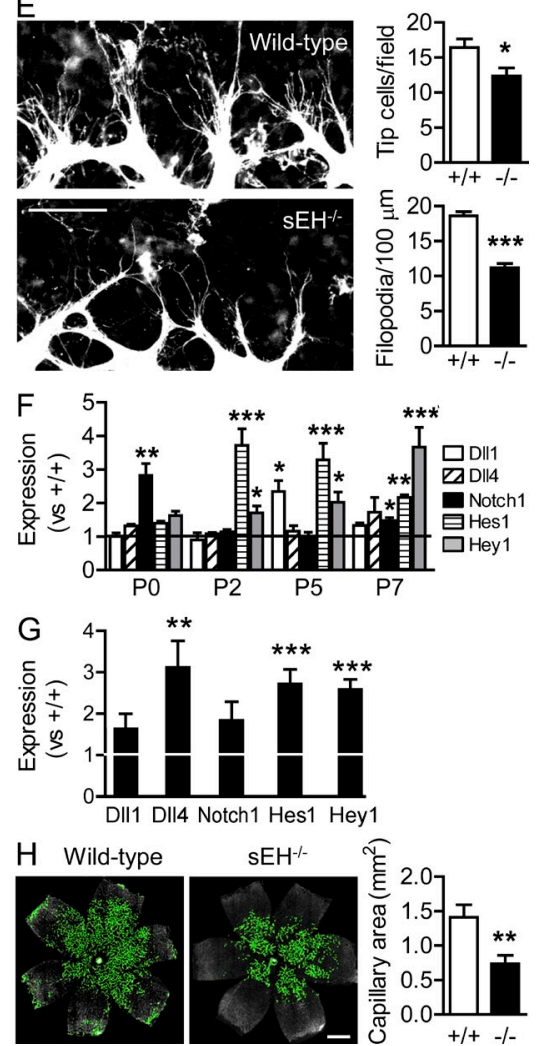

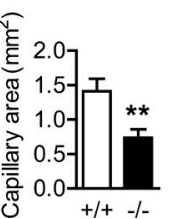

Figure 1. Delayed angiogenesis in $\mathrm{sEH}^{-1-}$ retinas. (A) Expression of the $\mathrm{SEH}$ in liver and retina from wild-type $(+/+)$ and $\mathrm{SEH} \mathrm{H}^{-1-}(-/-)$ mice was analyzed by Western blotting. (B) SEH activity in liver, spleen, lung, and retinas from wild-type and retinas from $\mathrm{SEH}^{-1-}$ mice as assessed by monitoring the generation of 14,15-DHET from 14,15-EET. Liver extracts were incubated with $10 \mu \mathrm{mol} /$ liter of the sEH inhibitor 1-adamantyl-3-cyclohexylurea (ACU) for 20 min. $n=4-6$ animals per group. (C) Isolectin B4 staining was assessed in whole mounts of the retinal vasculature in wild-type $(+/+)$ and $\mathrm{SEH}^{-1-}(-/-)$ mice by confocal microscopy on P2, P5, and P7. The front and central areas analyzed on $P 5$ retinas are indicated by white and orange boxes, respectively. Bars, $500 \mu \mathrm{m}$. The bar graphs summarize data from 1-3 animals per group in each experiment and experiments were independently performed 3 times. (D) BrdU (red) and Isolectin $\mathrm{B} 4$ (blue) levels in wild-type and $\mathrm{SEH}^{-1-}$ retinas (P5) were assessed by confocal microscopy. Bar, $100 \mu \mathrm{m} . n=2$ animals per group in each experiment and experiments were independently performed 3 times. (E) High magnification images and quantification of Isolectin B4-stained tip cells and filopodia (P5). Bar, $50 \mu \mathrm{m} . n=10$ animals per group. (F) Notch pathway gene expression in $\mathrm{sEH}^{-1-}$ retinas (P5) relative to wild-type $(+/+)$ was assessed by RT-qPCR. Each sample was a pool of 3 retinas, and the assay was performed on 4 independent samples. (G) Notch pathway gene expression was assessed by RT-qPCR in isolated retinal endothelial cells from $\mathrm{sEH} \mathrm{H}^{-1-}$

mice at P5 relative to wild-type (+/+). Each sample was a pool of 6 retinas, and the assay was performed on 4 independent samples. (H) Isolectin B4 staining of the deeper capillary vessel network in wild-type and $\mathrm{SEH}^{-1-}$ P9 retinas was assessed by confocal microscopy. Bar, $500 \mu \mathrm{m}$. $n=9$ for wild-type and $n=11$ for sEH ${ }^{-1-}$ mice from a total of 5 different experiments. Error bars represent SEM. ${ }^{*}, \mathrm{P}<0.05 ;{ }^{* *}, \mathrm{P}<0.01 ;{ }^{* * *}, \mathrm{P}<0.001$ versus wild-type.

EETs reported to induce angiogenesis in the chick chorioallantoic membrane (Michaelis et al.,2003) and the vascularization of Matrigel plugs implanted into wild-type mice (Medhora et al., 2003; Webler et al., 2008). Moreover, the overexpression of the human CYP2C11 and 2J2 enzymes in the ischemic rat hindlimb model was found to increase muscle capillary density (Wang et al., 2005). However, such studies could not address the importance of endogenously generated CYP metabolites and were difficult to back up in knockout models, as there are major differences in CYP epoxygenase isoform expression between species. This is particularly true for the CYP2C family of proteins, which have been most frequently linked to angiogenesis (Fleming, 2011). The majority of studies have also concentrated on the signaling initiated by the EETs, despite the fact that CYP isozymes can oxidize other $\omega-6$ and $\omega-3$ polyunsaturated fatty acids.

Intracellular levels of the lipid epoxides are carefully controlled and are determined by their rate of generation by the CYP enzymes, as well as by their metabolism to the corresponding diols by the soluble epoxide hydrolase (sEH; gene = Ephx2; Konkel and Schunck, 2011; Imig, 2012). The latter enzyme is highly conserved between species, and targeting its expression or activity in mice is an effective way of manipulating fatty acid epoxide and diol levels in vivo (Sinal et al., 2000). The aim of this study was to determine the consequences of sEH deletion/inhibition on retinal angiogenesis in mice and to use LC-MS/MS based lipid profiling to identify the lipid underlying the phenotype observed. Here, we report that an sEH-derived metabolite of the $\omega-3$ fatty acid DHA, rather than arachidonic acid, regulates murine retinal angiogenesis, and that a DHA diol generated by Müller glia cells is a major determinant of postnatal retinal angiogenesis via its ability to inhibit the $\boldsymbol{\gamma}$-secretase.

\section{RESULTS}

Delayed angiogenesis in $\mathrm{sEH}^{-l-}$ retina

sEH protein and activity were detected in retinas from adult and postnatal wild-type mice (Fig. 1 A), and although the 


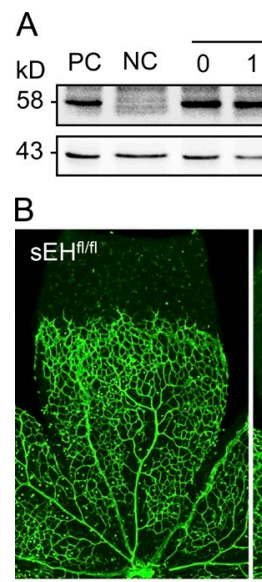

sEH ${ }^{\text {iKo }}$
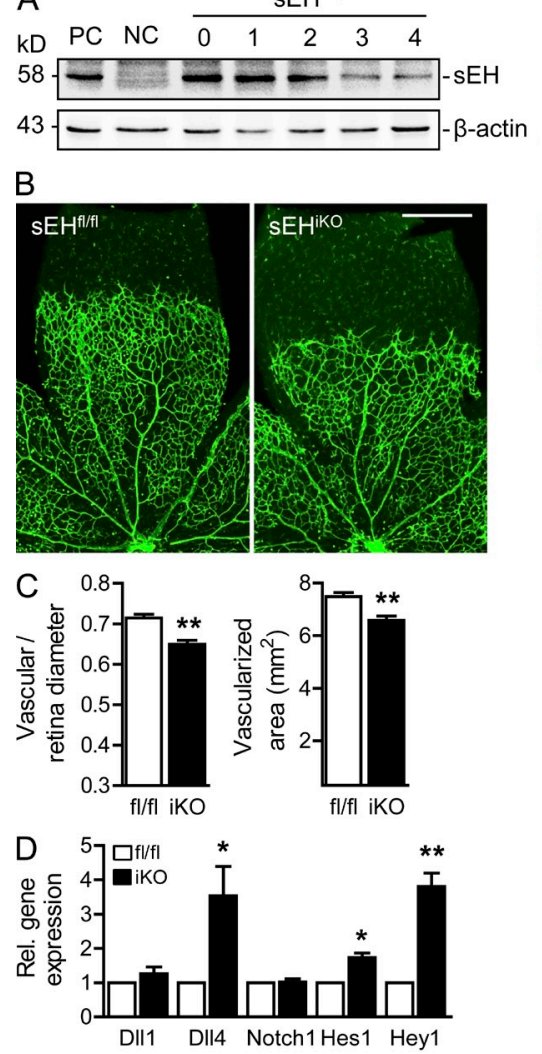

E
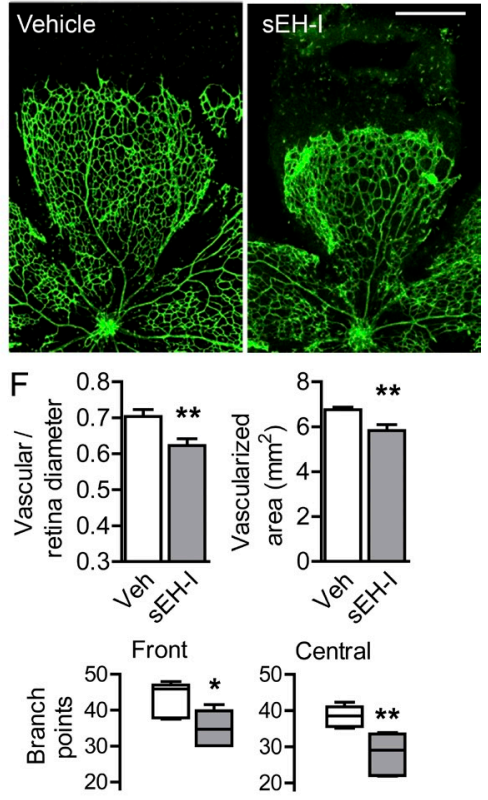

G $67 \square$ Veh

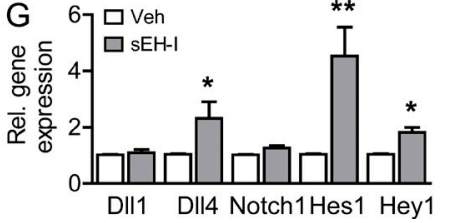

Figure 2. Consequences of the postnatal down-regulation and inhibition of the $\mathrm{SEH}$ on retinal angiogenesis. (A) $\mathrm{SEH}{ }^{\mathrm{K} O}$ mice were treated with tamoxifen from $\mathrm{P} 1$ to $\mathrm{P} 4$ and $\mathrm{sEH}$ expression was determined by Western blotting. Similar observations were obtained in 5 additional experiments. Retinas from wild-type and $\mathrm{SEH}^{-1-}$ mice were used as positive (PC) and negative (NC) controls, respectively. (B) Isolectin B4 staining in retinal whole mounts from tamoxifen-treated $\mathrm{sEH} \mathrm{H}^{\mathrm{flff}}$ and sEHiKo mice on P5. Bar, $500 \mu \mathrm{m}$. (C) Quantification of vascularization. $n=5$ total animals per group, from 3 different experiments. (D) Expression of genes involved in Notch signaling was assessed in P5 retinas by RT-qPCR. Each sample was a pool of 3 retinas, and the analysis was performed on 4 independent samples per genotype. (E) Wild-type mice were treated with vehicle (Veh) or sEH inhibitor (sEH-I) for $4 \mathrm{~d}$ and Isolectin B4 staining was analyzed by confocal microscopy. Bar, $500 \mu \mathrm{m}$. (F) Quantification of vascularization based in data in $\mathrm{E} . n=5-9$ total animals per group from 4 different experiments. (G) 5-d-old wild-type mice were treated with vehicle or SEH inhibitor for $4 d$, and Notch pathway gene expression was assessed by RT-qPCR. Each sample was a pool of 3 retinas, and the analysis was performed on 6 independent samples per genotype. Error bars represent SEM. ${ }^{*}, \mathrm{P}<0.05 ;{ }^{* *}, \mathrm{P}<0.01$ versus sEH $\mathrm{H}^{\mathrm{fl} / \mathrm{fl}}$ mice or vehicle. highest sEH activity was detected in the liver, activity in the retina was greater than that detected in either the spleen or lung (Fig. 1 B). To study the importance of the sEH in sprouting angiogenesis in vivo, we focused on retinal angiogenesis during the first postnatal week. sEH ${ }^{-/-}$mice displayed a significant delay in the radial extension of the vascular plexus from the optic nerve to the periphery at postnatal days 2 (P2) and 5 , as well as fewer branch points (Fig. $1 \mathrm{C}$ ). The delay in retinal angiogenesis in $\mathrm{sEH}^{-/-}$retinas at $\mathrm{P} 5$ was associated with a significant reduction in endothelial cell proliferation (BrdU incorporation) at the angiogenic front (Fig. 1 D) as well as with fewer tip cells and filopodia (Fig. 1 E).

Because all of these processes are highly dependent on the Notch pathway (Hellström et al., 2007; Tammela et al., 2008), our findings suggested that Notch signaling may be activated in the $\mathrm{SEH}^{-/-}$animals. We therefore studied the expression of the Notch receptor and ligands as well as the Notch downstream targets Hes1 and Hey1. Retinal Hey1 increased from $\mathrm{P} 2$ to $\mathrm{P} 7$ in $\mathrm{sEH}{ }^{-/-}$retina, whereas Hes1 levels were elevated in $\mathrm{sEH}^{-/-}$retina on $\mathrm{P} 2$ and $\mathrm{P} 5$ but decreased by $\mathrm{P} 7$ (Fig. $1 \mathrm{~F}$ ). Notch1 was up-regulated in $\mathrm{sEH}^{-/-}$mice immediately after birth (P0) but RNA levels then decreased (after P2). A transient increase in retinal delta-like ligand (D1l) 1 was detected on P5 but there were no significant changes in D114, which is also a target of activated Notch receptors (Phng and Gerhardt, 2009). A more detailed analysis of purified (CD31 beads) $\mathrm{sEH}^{-/-}$retinal endothelial cells confirmed the significant up-regulation of Dll4, Hes1, and Hey1 in 5-d-old sEH ${ }^{-/-}$mice (Fig. 1 G). Although coverage of the retina by the primary vascular layer was almost complete at day 7 in both genotypes, delayed angiogenesis persisted so that the formation of the secondary capillary plexus was also attenuated at $\mathrm{P} 9$ in $\mathrm{sEH}^{-/-}$mice (Fig. $1 \mathrm{H}$ ).

Different approaches were taken to ensure that the phenotype observed was related to the lack of sEH activity during retinal development. First, floxed $s E H$ mice $\left(s E H^{\mathrm{f} / \mathrm{fl}}\right)$ mice were bred with CreERT2 mice to generate an inducible sEH knockout strain ( $\mathrm{SEH}^{\mathrm{iKO}}$ ). Then $\mathrm{sEH} \mathrm{iKO}^{\mathrm{iKO}}$ pups were treated (on P1) with tamoxifen for $4 \mathrm{~d}$, a procedure which decreased sEH expression by $\sim 80 \%$ from day 3 onwards (Fig. 2 A). The acute postnatal down-regulation of the sEH also attenuated retinal angiogenesis and increased retinal expression of Dll4, Hes1, and Hey1 (Fig. 2, B-D). The apparent difference in the $\mathrm{sEH}^{-/-}$and $\mathrm{sEH}{ }^{\mathrm{iKO}}$ retinas can be most likely attributed to the fact that the $\mathrm{sEH}$ was still expressed at day 2 in the latter group of animals. The mammalian sEH protein is a homodimer, and each monomer consists of an N-terminal domain which displays lipid phosphatase activity and a larger $C$ terminal which possesses classical $\alpha / \beta$-hydrolase activity (Cronin et al., 2003; Newman et al., 2003). Therefore, in a second approach to ensure that the defects observed in the sEH ${ }^{-/-}$mice were due to the loss of epoxide hydrolase activity, newborn wild-type mice were treated with trans-4-[4-(3-adamantan-1-ylureido)cyclohexyloxy]benzoic acid (t-AUCB), a specific sEH inhibitor which does not affect the activity of the lipid phosphatase domain (Hwang 
A

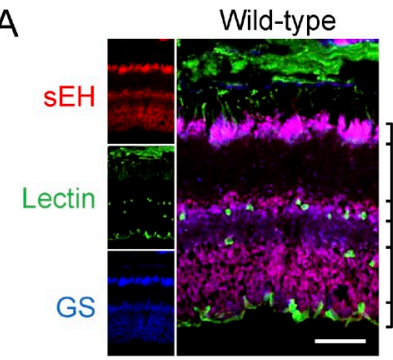

C

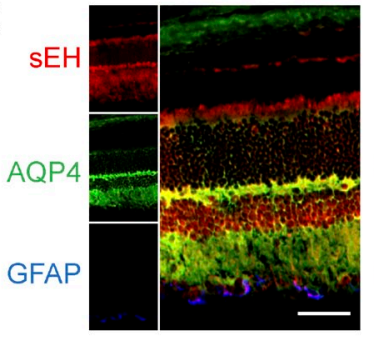

$\mathrm{F}$
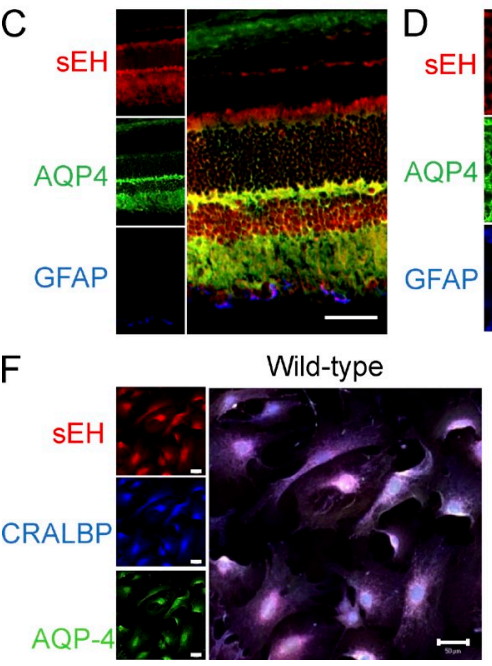
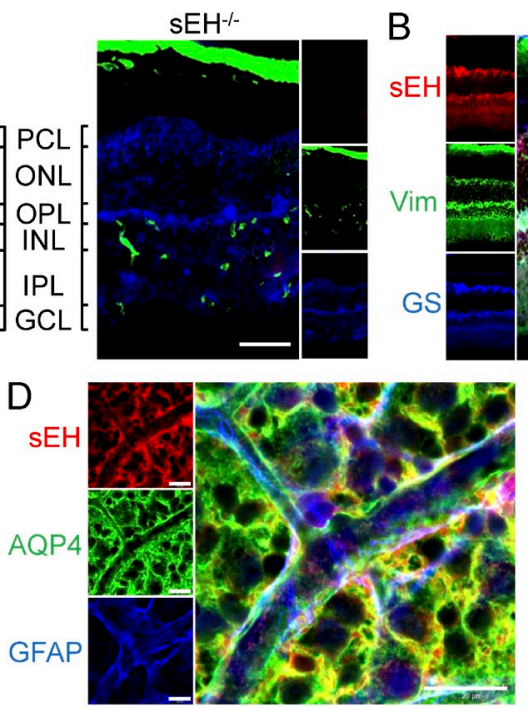

$\mathrm{SEH}^{-/-}$

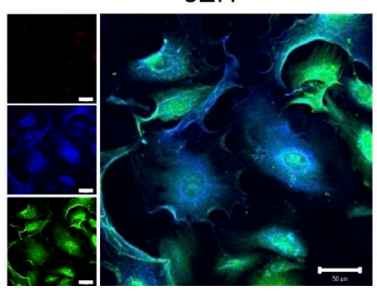

Figure 3. Localization of $s E H$ in the retina. (A) sEH (red), Isolectin B4 (green), and GS (blue) levels in retinal cryosections from wildtype and $\mathrm{SEH}^{-1-}$ mice were assessed by confocal microscopy. GCL, ganglion cell layer; IPL, inner plexiform layer; INL, inner nuclear layer; $\mathrm{OPL}$, outer plexiform layer; $\mathrm{ONL}$, outer nuclear layer; $P C L$, retinal pigment cell layer. Bars,

$50 \mu \mathrm{m}$. (B and C) sEH and vimentin (Vim) and GS (B) or AQP-4 and GFAP (C) expression in wildtype retinas was assessed by confocal microscopy. Bars, $50 \mu \mathrm{m}$. Similar observations were made in 4 additional experiments. (D) $\mathrm{SEH}$, AQP -4 , and GFAP expression in whole mounts of wild-type retinas assessed by confocal microscopy. Bars, $20 \mu \mathrm{m}$. Similar observations were made in retinas from 4 additional experiments. (E) SEH and AQP-4 expression in freshly isolated Müller cells from a wild-type retina. Bars, $20 \mu \mathrm{m}$. Similar observations were obtained in 4 independent experiments each using cells isolated from different litters. (F) Expression of $s E H, C R A L B P$, and AQP- 4 in primary cultures of Müller cells isolated from wild-type and $\mathrm{sEH}^{-1-}$ retinas. Bars, $50 \mu \mathrm{m}$. Similar observations were obtained in 4 independent experiments each using cells isolated from different litters. et al., 2007). Daily inhibitor treatment from P1 onwards significantly decreased retinal vascularization (assessed at P5) compared with vehicle-treated littermates, and this delay was accompanied by a significant increase in the expression of Dll4, Hes1, and Hey1 (Fig. 2, E-G).

\section{Expression of the sEH in Müller glia cells and astrocytes} In retinal cross sections, the $\mathrm{sEH}$ was detected in the ganglion cell, inner plexiform, and outer plexiform layers but did not colocalize with the Isolectin B4 staining of the vasculature. Rather, the sEH colocalized with glutamine synthase (GS; Fig. 3 A), as well as vimentin (Fig. 3 B), aquaporin 4 (AQP-4), and, to a certain extent, glial fibrillary acidic protein (GFAP; Fig. 3 C). In whole mount preparations, the sEH was detected in short AQP-4-positive processes surrounding the vasculature but not in the vessels themselves-i.e., consistent with expression in Müller cell processes (Fig. 3 D). Indeed, Müller cells freshly isolated from adult retinas displayed the typical morphology with multiple end-feet and expressed the sEH protein (Fig. 3 E). Although the morphology of the Müller cells in culture was markedly different from that of freshly isolated cells, they continued to express the $\mathrm{sEH}$, as well as AQP-4 and the Müller cell marker cellular retinaldehyde binding-protein (CRALBP; Bunt-Milam and Saari, 1983; Fig. 3 F).

To target $\mathrm{sEH}$ expression in Müller cells, $\mathrm{sEH} \mathrm{H}^{\mathrm{f} / \mathrm{fl}}$ mice were crossed with platelet-derived growth factor receptor $\alpha$ polypeptide (Pdgfra)-cre deleter mice (Roesch et al., 2008). The resulting Müller cell-specific sEH knockout mice $\left(\mathrm{sEH}^{\Delta \mathrm{MC}}\right)$ showed a greatly reduced expression of the $\mathrm{sEH}$ in the inner and outer plexiform layers of the retina (Fig. 4 A), decreased retinal epoxide hydrolase activity (Fig. 4 B), and reproduced the delay in angiogenesis (Fig. 4, C-E) as well as the altered tip cell morphology (Fig. 4, F-H) of the $\mathrm{sEH}^{-/-}$ mice. These phenomena were also linked to altered Notch signaling, as Hes1 and Hey1 expression were also increased in retinas from 5-d-old sEH ${ }^{\Delta M C}$ mice (Fig. 4 I).

Several studies have highlighted the role of the astrocyte framework as a template for the primary plexus outgrowth as well as a source of angiogenic growth factors (Stone and Dreher, 1987; Gerhardt et al., 2003). Given that the sEH is expressed in astrocytes (Rawal et al., 2009) and that the sEH was partially colocalized with GFAP, we generated mice with astrocyte-specific deletion of the $\mathrm{sEH}\left(\mathrm{sEH}^{\mathrm{t} / \mathrm{fl}}\right.$ mice crossed with GFAP-cre deleter mice). Astrocyte-specific deletion of the sEH (Fig. $5 \mathrm{~A}$ ) resulted in the development of a less dense upper capillary layer characterized by fewer branching points in central areas and at the leading edge (Fig. 5 B). The marked delay in radial extension observed in global $\mathrm{sEH}^{-/-}$mice was, however, not observed. In addition, tip cell numbers and filopodia length were comparable in $\mathrm{sEH}^{\mathrm{f} / \mathrm{fl}}$ and GFAP-sEH mice (Fig. 5 C), as were the expression of Hes1 and Hey1 (Fig. 5 D). These data indicated that the sEH expressed in Müller cells played a more prominent role in regulating angiogenesis than the $\mathrm{sEH}$ in astrocytes.

\section{Müller cell lipid profile}

Müller cells are a rich source of angiogenesis-promoting growth factors, in particular vascular endothelial cell growth 
A
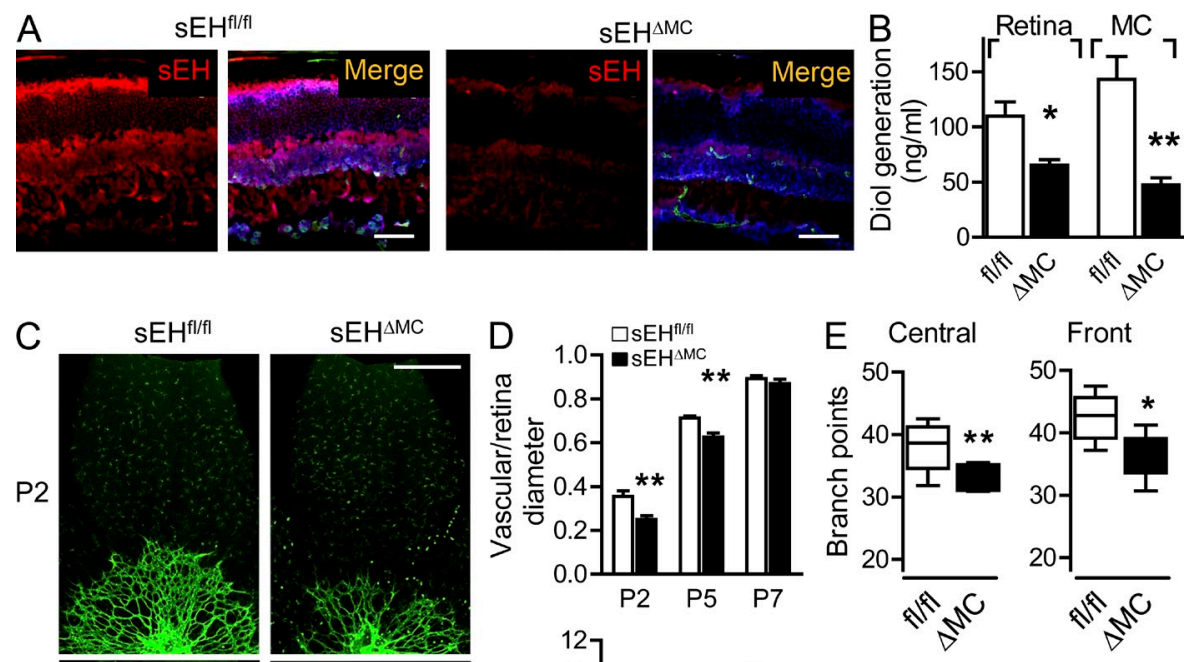

Front
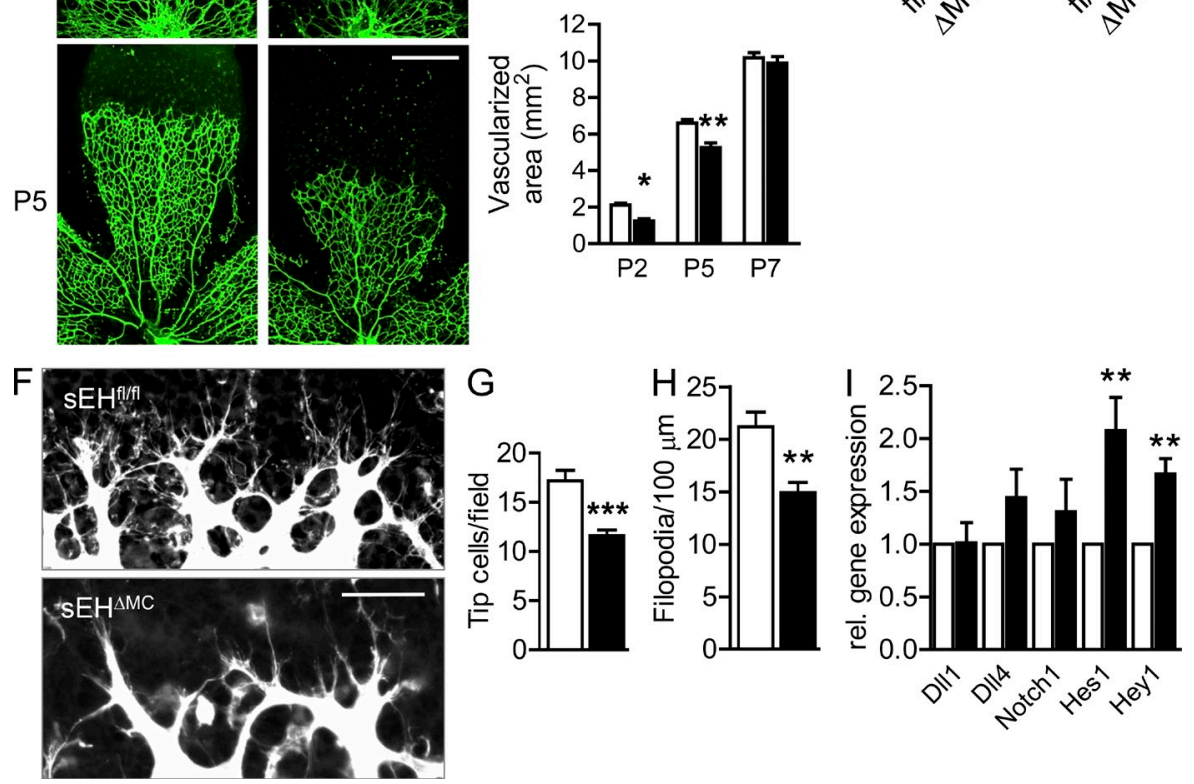

Figure 4. Angiogenesis in Müller cellspecific sEH knockout mice. (A) SEH expression (red) in cryosections from $\mathrm{SEH}^{\mathrm{fl} / \mathrm{fl}}$ and $\mathrm{sEH}{ }^{\triangle \mathrm{MC}}$ littermates. Bars, $50 \mu \mathrm{m}$. Endothelial cells were identified using Isolectin B4 (green), and Müller cells by GS (blue) using confocal microscopy. Similar observations were made in 4 additional experiments. (B) SEH activity was assessed by LC-MS/MS in fresh retinas and cultured Müller cells (MCs) from $\mathrm{SEH} \mathrm{H}^{\mathrm{fl} / \mathrm{fl}}$ and $\mathrm{sEH} \mathrm{HMC}^{\Delta \mathrm{MC}}$ littermates. Each sample was a pool of 3 retinas, and the analysis was performed on 4 independent samples per genotype (graph shows pooled data from the four analyses). (C) Isolectin $\mathrm{B} 4$ staining of retinal whole mounts of $\mathrm{P} 2$ and $\mathrm{P} 5$ retinas from $\mathrm{sEH} \mathrm{F}^{\mathrm{fl} / \mathrm{fl}}$ and $\mathrm{SEH} \mathrm{HMC}^{\Delta \mathrm{MC}}$ mice. Bars, $500 \mu \mathrm{m}$. (D and E) Quantification of vessel radial expansion (D), vascularized area, and vessel branch points $(\mathrm{E})$ in $\mathrm{SEH}^{\mathrm{fl} / \mathrm{fl}}$ and $\mathrm{sEH}{ }^{\Delta \mathrm{MC}}$ mice at P5 based in data in C. $n=5-7$ total mice from 3-4 different experiments. (F) Isolectin B4-stained tip cells and filopodia at P5 assessed by confocal microscopy. Bar, $50 \mu \mathrm{m}$. ( $\mathrm{G}$ and $\mathrm{H}$ ) Quantification of tip cells $(G)$ and filopodia numbers $(H)$ in P5 retinas based on data in F. $n=6$ total mice from 3-4 different experiments. (I) Notch pathway gene expression in retinas from $s E H^{\Delta M C}$ relative to $s E H^{f \mid f l f l}$ mice was assessed by RT-qPCR. Each sample was a pool of 3 retinas, and the assay was performed on 4 independent samples per genotype. Error bars represent SEM. * $\mathrm{P}<0.05$; ${ }^{*}, \mathrm{P}<0.01$; ***, $P<0.001$ versus SEH ${ }^{f / / f l}$. factor (VEGF) A (Pierce et al., 1995; Stone et al., 1995). Therefore, we compared the effects of conditioned medium (CM) from wild-type and $\mathrm{sEH}^{-/-}$Müller cells on endothelial cell proliferation. CM from sEH-expressing Müller cells potentiated endothelial cell proliferation, whereas the CM from sEH ${ }^{-/-}$Müller cells exhibited a weaker effect (Fig. 6 A). There were no differences in VEGFR1,VEGFR2, or VEGFR3 expression in retinas from wild-type and $\mathrm{sEH}^{-/-}$mice over the first postnatal week (unpublished data). VEGF levels were also similar in whole retinas from wild-type and $\mathrm{sEH}^{-/-}$mice up to day 9 (Fig. 6 B), but the generation of VEGF was reduced in Müller cells and in CM from sEH ${ }^{-/-}$mice (Fig. 6, $\mathrm{C}$ and $\mathrm{D})$. The expression of the anti-angiogenic pigment epithelium-derived factor (Dawson et al., 1999) was not different in CM from wild-type and $\mathrm{SEH}^{-/-}$Müller cells. Despite the apparent difference in VEGF secretion, VEGF neutralizing antibodies elicited similar effects on endothelial cells treated with wild-type-CM or sEH ${ }^{-/-}$-CM (Fig. 6 E).

However, a soluble factor was responsible for the observed phenotype, as when sEH ${ }^{-/-}$Müller cells were co-cultured with, but kept physically separated from, endothelial cells (Transwell chambers), endothelial cell proliferation (assessed by BrdU incorporation) was attenuated. Moreover, the reexpression (adenoviral transduction) of the sEH in Müller cells normalized endothelial cell proliferation (Fig. 6 F). Similarly, the expression of Hes1 and Hey1 increased in endothelial cells cultured with $\mathrm{sEH} \mathrm{H}^{-/-}$versus wild-type Müller cells (Fig. $6 \mathrm{G}$ ), and a rescue experiment, in which the sEH was reintroduced into $\mathrm{SEH}^{-/-}$Müller cells, reversed these effects.

To determine which of the sEH substrates or products could account for the delay in retinal angiogenesis, lipid profiles (LC-MS/MS) were generated from the retinas of 5-d-old wild-type and sEH ${ }^{-1-}$ mice. As expected, levels of 11,12- and 14,15-EET were increased in samples from $\mathrm{sEH}{ }^{-/-}$mice, whereas the levels of the corresponding diols were slightly decreased (Fig. 7 A). However, the most pronounced changes were in the levels of the DHA derivative 19,20-dihydroxydocosapentaenoic acid (DHDP). In CM from $\mathrm{sEH}^{-/-}$Müller cells, 11,12-EET, 14,15-EET, and 19,20epoxydocosapentaenoic acid (EDP) levels were significantly 
A

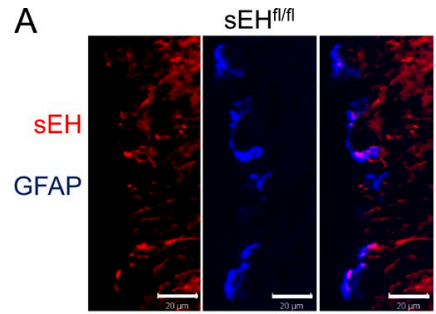

B $\quad s E H^{\text {IIf }}$

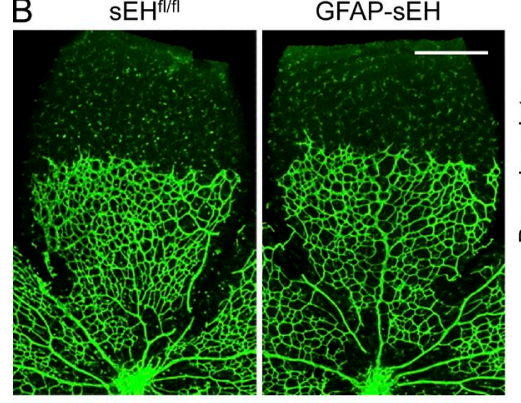

GFAP-SEH

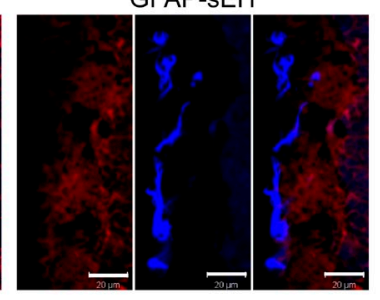

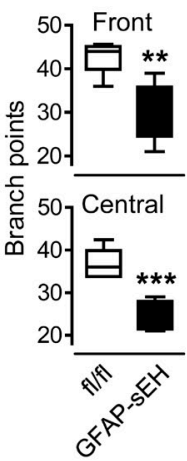

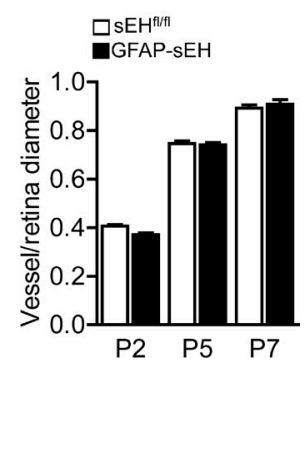

C
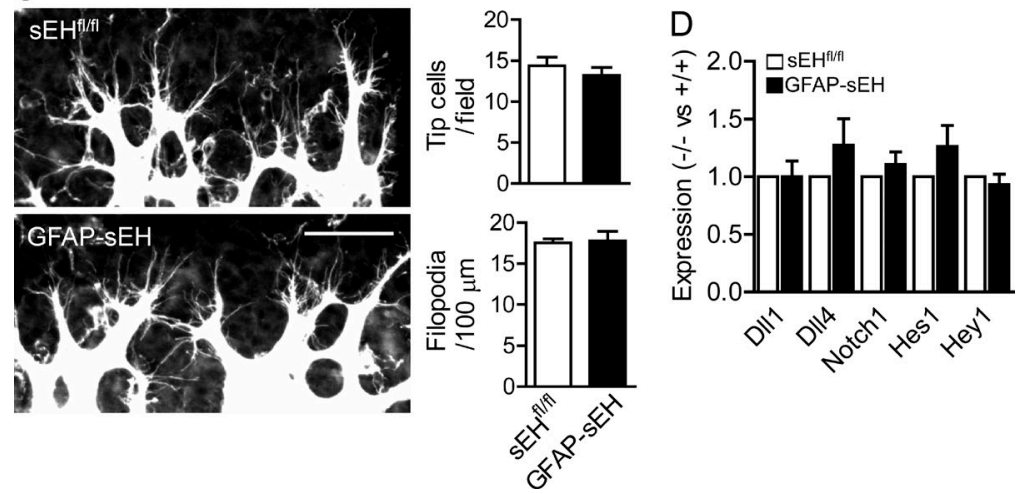

Figure 5. Angiogenesis in astrocyte-specific $\mathrm{SEH}$ knockout mice. (A) sEH and GFAP expression in $\mathrm{sEH}^{\mathrm{flff}}$ and astrocyte-specific sEH knockout (GFAP-sEH) littermates was assessed by confocal microscopy. Bars, $20 \mu \mathrm{m}$. Similar observations were made in 4 additional experiments. (B) Isolectin B4 staining of retinal whole mounts from $\mathrm{sEH} / \mathrm{flf}$ and GFAPsEH mice at P5 was assessed and quantified by confocal microscopy. Bar, $500 \mu m . n=5-7$ total mice from 3-4 different experiments. (C) Isolectin B4-stained tip cells and filopodia in retinas from $\mathrm{SEH} \mathrm{H}^{\mathrm{flff}}$ and GFAP-sEH mice at P5 was assessed and quantified by confocal microscopy. Bar, $50 \mu \mathrm{m} . n=6$ total mice from 3-4 different experiments. (D) Notch pathway gene expression in sEHff/ll and GFAP-sEH P5 retinas was assessed by RT-qPCR. Each sample was a pool of 3 retinas, and the analysis was performed on 4 independent samples per genotype. Error bars represent SEM. ${ }^{* *}, \mathrm{P}<0.01 ; * *, \mathrm{P}<0.001$ versus sEH $\mathrm{H}^{\mathrm{f} / \mathrm{f}}$. increased in CM and were restored to control by adenoviral transduction of the sEH (Fig. 7 B). The opposite was true for 19,20-DHDP, which was attenuated in CM from $\mathrm{sEH}^{-/-}$ Müller cells and restored by sEH overexpression. There was no significant change in 11,12-dihydroxyeicosatrienoic acid (DHET) levels, 14,15-DHET levels were below the limit of detection, and there were no apparent changes in the levels of the linoleic acid-derived fatty acids, 12,13epoxyoctadecenoic acid (EpOME), or 12,13-dihydroxyoctadecenoic acid (DiHOME).

\section{9,20-DHDP and Notch signaling}

19,20-DHDP is of particular interest, given that it was the most abundant lipid detected in the retinal lipid profile and that its precursor DPA has previously been reported to modulate the activity of the $\gamma$-secretase (Delbosc et al., 2008; Grimm et al., 2011). When activated, the $\gamma$-secretase cleaves the Notch intracellular domain (NICD), which then either undergoes rapid proteasome degradation or translocates to the nucleus and binds to transcription factors (Boulton et al., 2008). We therefore compared the ability of 19,20DHDP and the corresponding epoxide and $\mathrm{sEH}$ substrate 19,20-EDP to influence Dll4-stimulated Notch activity in murine endothelial cells. Although 19,20-EDP had no effect on the Dll4-induced increase in NICD cleavage, 19,20DHDP decreased NICD levels by $54 \pm 12 \%$ versus $89 \pm 7 \%$ inhibition in the presence of the $\gamma$-secretase inhibitor $N-[N-$ (3,5-Difluorophenacetyl)-L-alanyl]-S-phenylglycine t-butyl ester (DAPT; Fig. 7 C). Neither 19,20-EDP nor 19,20-DHDP affected VEFGR phosphorylation or downstream signaling in vascular endothelial cells (unpublished data). Treatment of cells with other sEH substrates, e.g., 11,12-EET, 14,15-EET, or 12,13-EpOME, or products, e.g., 11,12-DHET, 14,15DHET, or 12,13-DiHOME, that were altered in the $\mathrm{sEH}^{-/-}$ retinas had no effect on the Dll4-induced cleavage of NICD (Fig. 7, D-F). When the nuclear translocation of the NICD was assessed by immunofluorescence (Fig. 8 A), 19,20-DHDP, but not 19,20-EDP, attenuated the Dll4-stimulated translocation. The fact that 19,20-DHDP also attenuated NICD levels in the presence of the proteasome inhibitor MG 132 (Fig. 8 B) suggested that the generation of the NICD, rather than its degradation, was targeted by the lipid.

The binding of a Notch ligand to a Notch receptor initiates two steps of cleavage to generate the NICD, the first by ADAM (a disintegrin and metalloprotease) proteases and the second by the $\gamma$-secretase (Kopan and Ilagan, 2009). The 

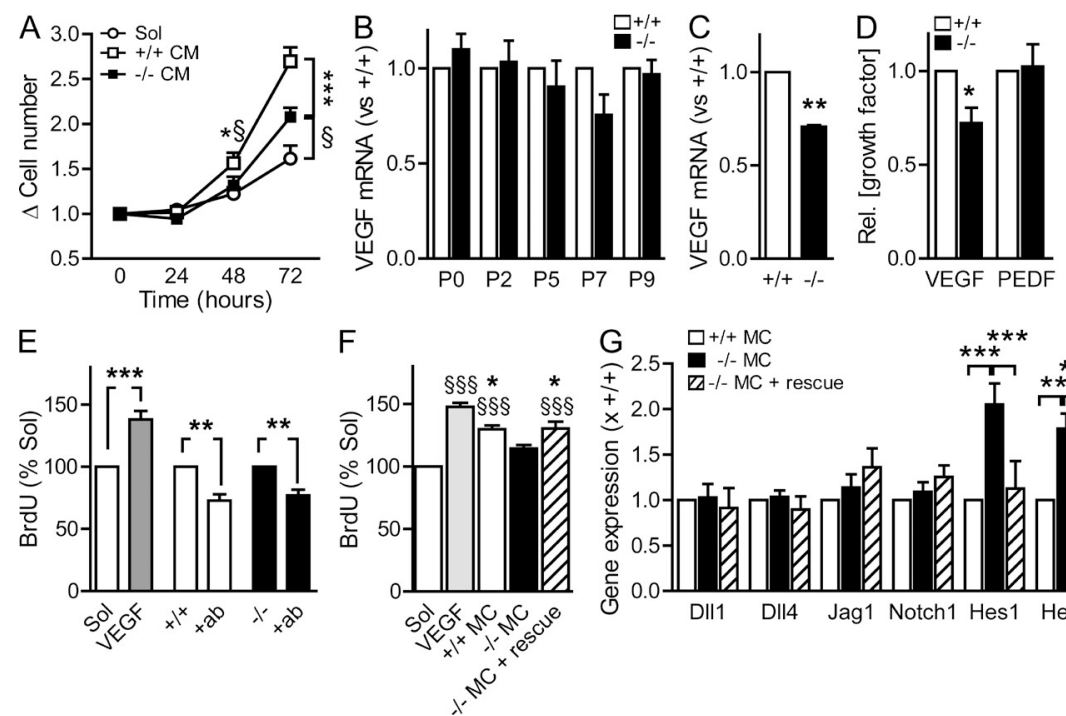

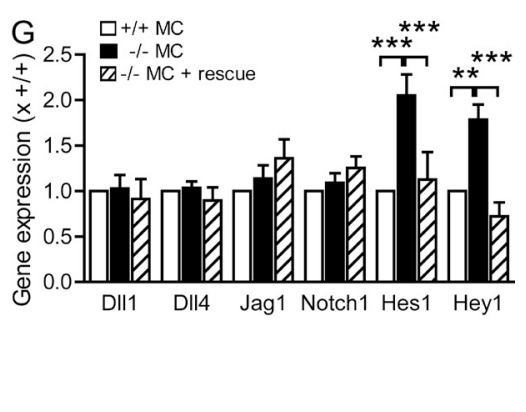

Figure 6. A Müller cell-derived lipid regulates endothelial Notch signaling. (A) Endothelial cell proliferation in the presence of solvent (DMEM/F12) or the CM from wild-type $(+1+)$ or $\mathrm{sEH}^{-1-}(-1-)$ Müller cells was assessed by cell counting. The bar graph summarizes the data from 4 independent experiments each using different cell batches. (B) VEGF gene expression in wild-type and $\mathrm{sEH}^{-1-}$ mice retinas assessed by RT-qPCR. Each sample was a pool of 3 retinas, and the analysis was performed on 4 independent samples per genotype. (C) VEGF gene expression in primary cultures of Müller cells from wild-type $(+/+)$ and $\mathrm{sEH}^{-1-}(-/-)$ mice. Data were obtained from 4 different cell batches. (D) Relative VEGF and pigment epithelium-derived factor (PEDF) concentrations in CM from wild-type and $\mathrm{SEH}^{-1-}$ Müller cells. Data were obtained from 3 different cell batches. (E) BrdU incorporation in murine lung endothelial cells after treatment with CM from wild-type or $\mathrm{sEH}{ }^{-1-}$ Müller cells in the absence and presence of a VEGF neutralizing antibody (+ab) was assessed by ELISA. $50 \mathrm{ng} / \mathrm{mI}$ VEGF was used as positive control. The bar graph summarizes data from 6 independent experiments, each using a different cell batch. (F) BrdU incorporation in $\mathrm{sEH}^{-1-}$ endothelial cells after treatment with $\mathrm{CM}$ for $48 \mathrm{~h}$ was assessed by ELISA. In the rescue group, the sEH was adenovirally overexpressed in sEH-I- Müller cells. $50 \mathrm{ng} / \mathrm{ml}$ VEGF was used as a positive control. The experiment was performed 6 times with 6 different cell batches. $(G)$ Notch pathway gene expression in murine endothelial cells after co-culture with Müller cells $(M C)$ from wild-type $(+/+), s E H^{-1-}(-/-)$ mice with or without the adenoviral transduction of the SEH $(-1-+$ rescue) was assessed by RT-qPCR. The experiment was performed 4 times using 4 different cell batches. Error bars represent SEM. ${ }^{*}, \mathrm{P}<0.05 ;{ }^{* *}, \mathrm{P}<0.01 ;{ }^{* *}, \mathrm{P}<0.001$ versus $\mathrm{sEH}{ }^{-1-}$. $\S, \mathrm{P}<0.05 ; \S \S \S, \mathrm{P}<0.001$ versus solvent.

effect of 19,20-DHDP on the $\boldsymbol{\gamma}$-secretase was evaluated using cells expressing a Notch 1 mutant (Notch $\Delta E$ ) that lacks the extracellular domain of the protein and possesses only the $\gamma$-secretase cleavage site (He et al., 2010). We found that
19,20-DHDP, but not 19,20-EDP, reduced the $\boldsymbol{\gamma}$-secretasedependent generation of NICD from Notch $\Delta \mathrm{E}$ (Fig. 8 C). The small effect observed at higher concentrations of 19,20EDP can most likely be attributed to the endogenous expression
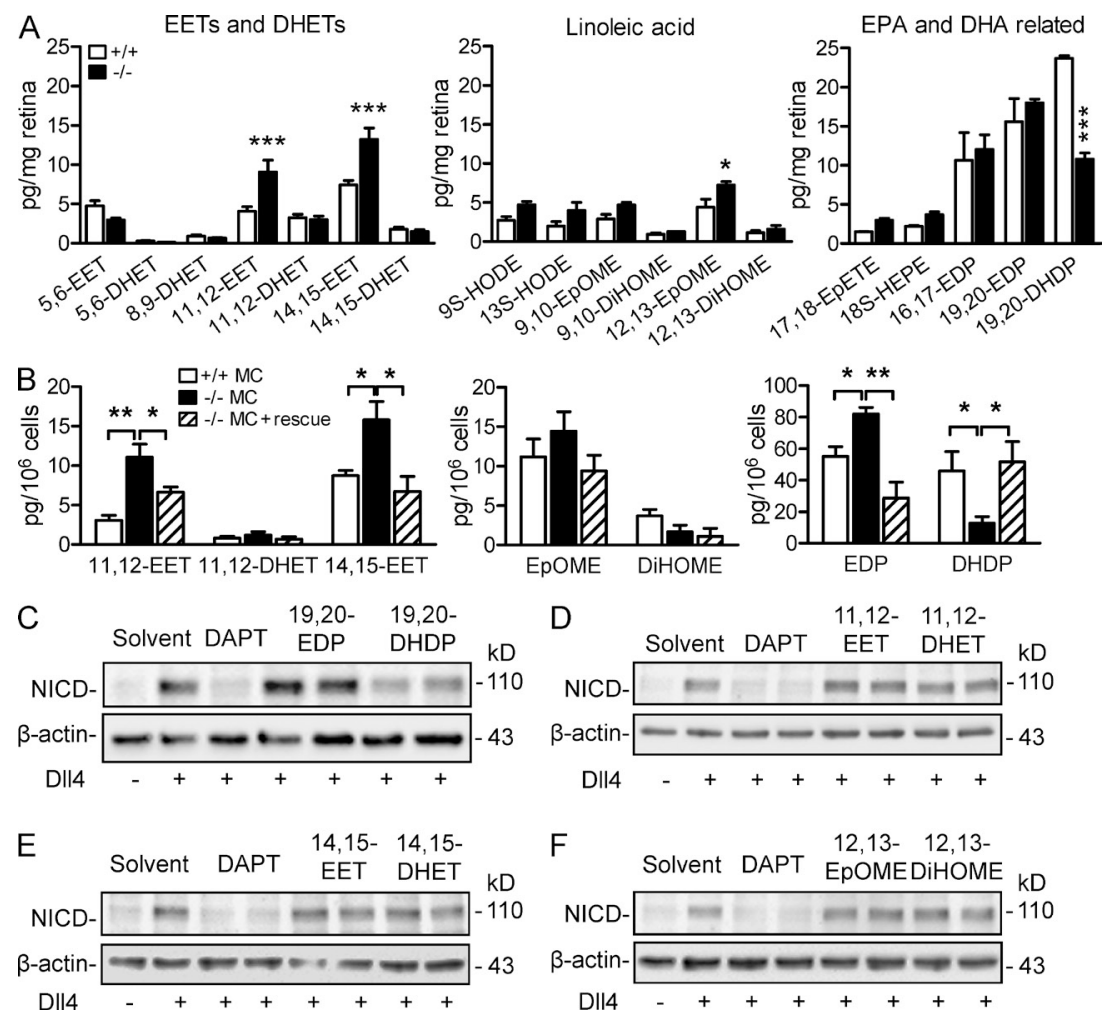

Figure 7. Lipid profile of wild-type and $\mathrm{sEH}^{-1-}$ retinas and effect of lipids on DII4-induced NICD production. (A) Lipid profile of retinas (P5) from wild-type $(+/+)$ and $\mathrm{SEH}^{-1-}(-/-)$ littermates was assessed by LC-MS/MS. HODE: hydroxyoctadecadienoic acid; EpETE: epoxyeicosatetraenoic acid; HEPE: hydroxyl-EPE. The data summarize results from 5 samples (each representing a pool of 5 retinas) examined independently. (B) The lipid profile of CM from wild-type and $\mathrm{sEH} \mathrm{EH}^{-1-}$ Müller cells, as well as $\mathrm{SEH}^{-1-}$ cells transduced with an $\mathrm{SEH}$ adenovirus $(-1-+$ rescue $)$, was assessed by LC-MS/MS. The data summarize results obtained in 5 separate experiments, each representing a different cell batch. ${ }^{*}, \mathrm{P}<0.05 ;{ }^{* *}, \mathrm{P}<0.01 ;{ }^{* * *}, \mathrm{P}<0.001$. (C-F) NICD levels, assessed by Western blotting, in $\mathrm{SEH}^{-1-}$ murine lung endothelial cells seeded onto plastic (-) or DII4 and treated with solvent, $20 \mu \mathrm{mol} /$ liter DAPT (C), $10 \mu \mathrm{mol} / \mathrm{liter} 19,20-$ EDP or 19,20-DHDP, $10 \mu \mathrm{mol} / \mathrm{liter} 11,12$-EET or 11,12-DHET (D), $10 \mu \mathrm{mol} /$ liter 14,15-EET or 14,15-DHET (E), and $3 \mu \mathrm{mol} /$ liter 12,13-EpOME or 12,13-DiHOME (F). For C-F, similar observations were made in at least 3 additional experiments, using cells from 3 different cell batches. Error bars represent SEM. 

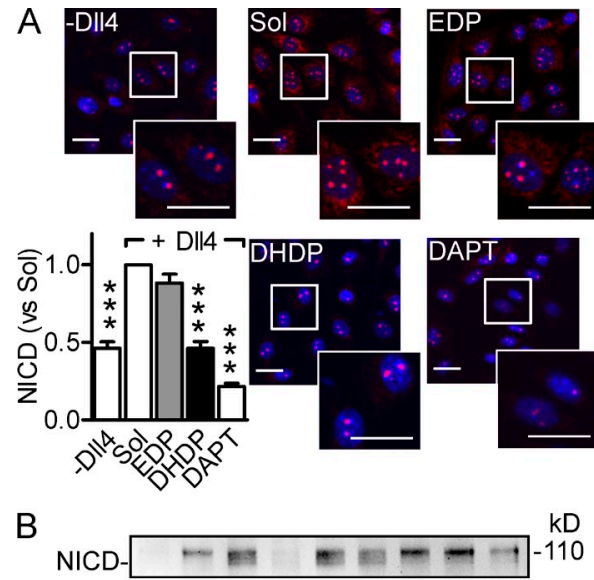
B-actin- $=\infty 600000-43$
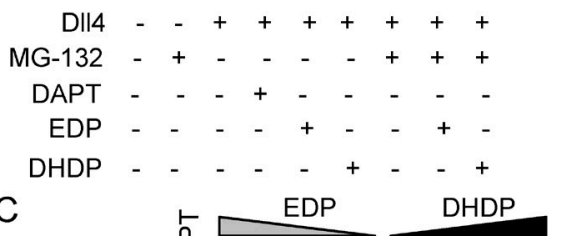

C

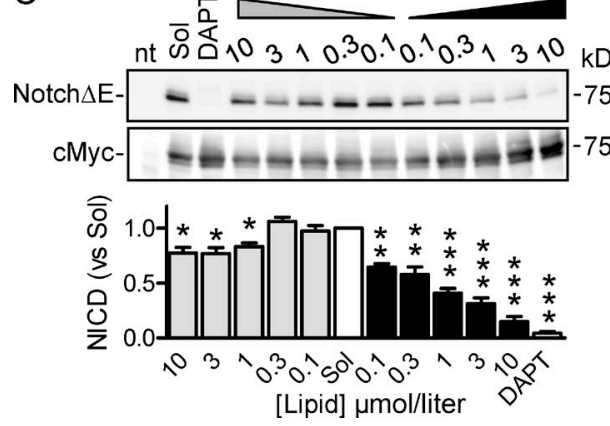

D Solvent $\mathrm{LR}$

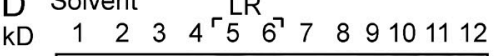

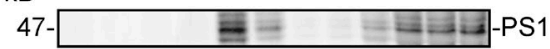

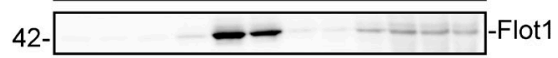

19,20-EDP LR

$\begin{array}{llllllllllll}1 & 2 & 3 & 4 & 5 & 6 & 7 & 8 & 9 & 10 & 11 & 12\end{array}$

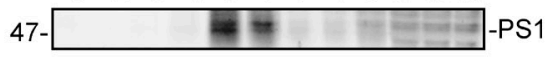

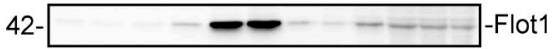

19,20-DHDP LR

$\begin{array}{llllllllllll}1 & 2 & 3 & 4 & 5 & 6 & 7 & 8 & 9 & 10 & 11 & 12\end{array}$
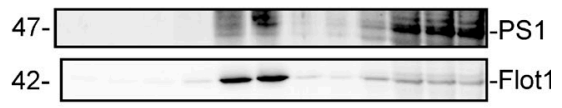

DAPT LR

$\begin{array}{lllllllllllll}1 & 2 & 3 & 4 & 5 & 6 & 7 & 8 & 9 & 10 & 11 & 12\end{array}$
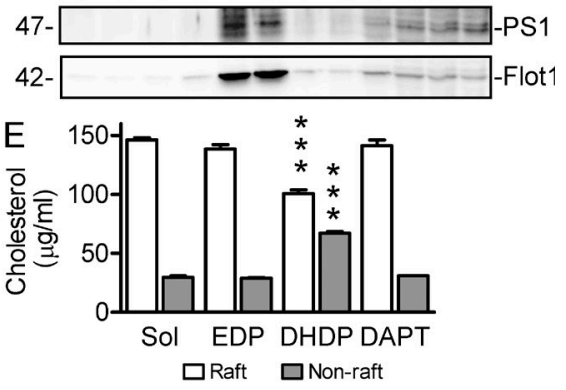

Figure 8. Effect of 19,20-EDP and 19,20DHDP on endothelial cell Notch signaling. (A) DII4-induced NICD nuclear translocation in $\mathrm{sEH} \mathrm{H}^{-1-}$ endothelial cells treated with solvent (Sol), $10 \mu \mathrm{mol} /$ liter 19,20-EDP, $10 \mu \mathrm{mol} /$ liter 19,20-DHDP, or $20 \mu \mathrm{mol} /$ liter DAPT was assessed by confocal microscopy. Endothelial cells cultured in the absence of D\|4 (-D\|4) served as a negative control. Bars, $20 \mu \mathrm{m}$. The graph summarizes data from 9 independent experiments using 4 different cell batches. (B) NICD levels in murine lung endothelial cells seeded onto plastic or DII4 were assessed by Western blotting. Experiments were performed in the absence and presence of $10 \mu \mathrm{mol} /$ liter MG-132, 20 umol/liter DAPT, $10 \mu \mathrm{mol} / /$ iter 19,20-EDP, or $10 \mu \mathrm{mol} /$ /iter 19,20-DHDP. Similar observations were obtained in 3 additional experiments using 3 different cells batches. (C) Relative $\gamma$-secretase activity was assessed by Western blotting for NICD generation in HEK cells overexpressing the Notch $\Delta \mathrm{E}$ mutant in the absence and presence of 19,20EDP, 19,20-DHDP (both 0.1-10 $\mu \mathrm{mol} /$ /iter), or DAPT. Nontransfected (nt) cells lacking the Notch $\Delta$ E served as control. Graph summarizes data from 4 independent experiments (4 different cell batches). (D) The distribution of presenilin 1 (PS1) and flotillin 1 (Flot1) in lipid rafts (LR; fractions 5 and 6) and non-raft fractions (10-12) after treatment with solvent (0.1\% DMSO), 10 umol/liter 19,20-EDP, 10 umol/liter 19,20DHDP, or $20 \mu \mathrm{mol} /$ liter DAPT was assessed by Western blotting. Comparable results were obtained in 3 additional experiments each using different cell batches. (E) Cholesterol concentrations in the raft and non-raft fractions assessed by the Amplex Red cholesterol assay. The graph summarizes data from 4 independent experiments. Error bars represent SEM. ${ }^{*}, \mathrm{P}<0.05$; ${ }^{* *}, \mathrm{P}<0.01 ;{ }^{* *}, \mathrm{P}<0.001$ versus solvent.

of the sEH in the cells used (Barbosa-Sicard et al., 2009) and its conversion to 19,20-DHDP.

The $\gamma$-secretase complex is made up of several proteins, including presenilin 1 , nicastrin, anterior pharynx defective 1 , and presenilin enhancer 2, and the active complex is localized to lipid rafts (Vetrivel et al., 2004; Hur et al., 2008; Vetrivel and Thinakaran, 2010). We therefore determined whether 19,20DHDP could inhibit the $\gamma$-secretase by altering the localization of constituent proteins and concentrated on presenilin 1. After sucrose density gradient fractionation, presenilin 1 and the raft-associated protein flotillin-1/reggie-2 were detected in detergent-insoluble lipid raft fractions (fractions 5 and 6) isolated from solvent-treated cells. 19,20-DHDP caused the displacement of presenilin 1 from lipid rafts to non-raft fractions (fractions 10 to 12) without affecting the distribution of flotillin-1 (Fig. 8 D). The latter effect that was accompanied by a decrease in cholesterol levels in the raft fractions (fractions 5 and 6) and an increase in the non-raft fractions (Fig. 8 E). Neither 19,20-EDP (in the presence of the $\mathrm{sEH}$ inhibitor
t-AUCB) nor DAPT affected the colocalization of presenilin 1 with flotillin-1 or the distribution of cholesterol between the different fractions.

Finally, we determined whether or not 19,20-DHDP could rescue the retinal phenotype in $\mathrm{SEH}^{-/-}$mice. Intravitreal injection of 19,20-DHDP was performed in 5-dold wild-type and $\mathrm{sEH}{ }^{-/-}$pups and its effects compared with that of DAPT-treated mice. As before, the $\mathrm{sEH}^{-1-}$ retinas demonstrated a less dense vessel network as well as fewer tip cells and filopodia than their wild-type littermates, but this phenotype was largely reversed after the administration of 19,20-DHDP (Fig. 9). Similar effects were observed in retinas from animals receiving DAPT, whereas 19,20-EDP was without effect. In retinas from wild-type mice, 19,20-DHDP (but not 19,20-EDP) also induced a more complex vessel network, and increased tip cell and filopodia numbers (Fig. 9).

The E3 ubiquitin ligase Fbxw7 is involved in the ubiquitination and degradation of the NICD (Tan et al., 2008; 

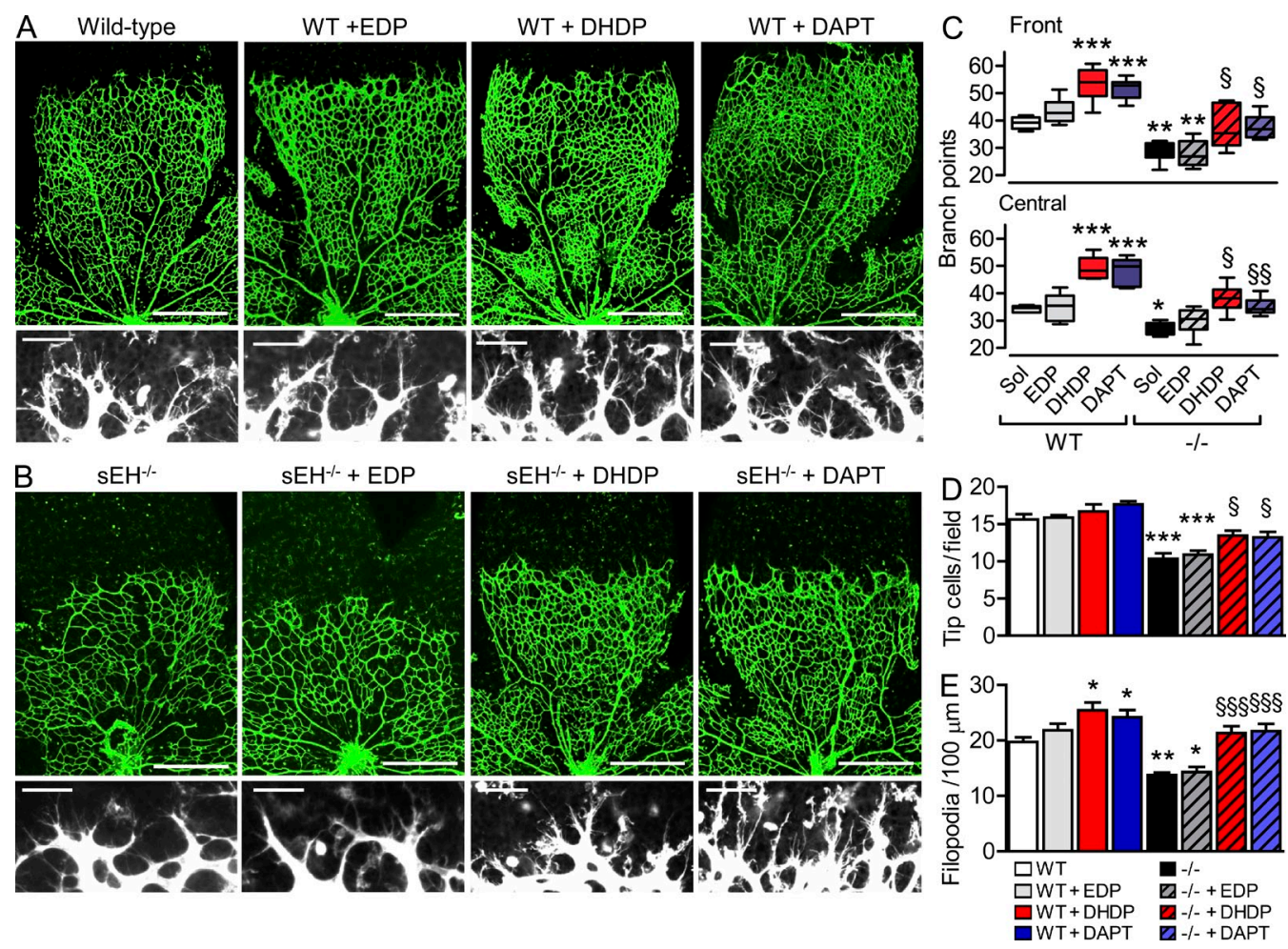

Figure 9. 19,20-DHDP promotes retinal angiogenesis in vivo. (A and B) Isolectin B4-stained retinal vasculature (top; bars, $500 \mu \mathrm{m})$ and tip cells at the angiogenic front (bottom; bars, $50 \mu \mathrm{m}$ ) of P5 retinas was assessed by confocal microscopy of whole mounts from wild-type (WT) mice (A) or sEH ${ }^{-1-}$ $\left(^{(-)}\right)$mice (B) $5 \mathrm{~h}$ after intravitreal injection of $0.5 \mu \mathrm{l}$ solvent, $100 \mu \mathrm{mol} /$ liter 19,20-EDP, $100 \mu \mathrm{mol} /$ liter 19,20-DHDP, or $200 \mu \mathrm{mol} / \mathrm{liter}$ DAPT. (C-E) The graphs summarize vessel branch points (C), tip cell (D), and filopodia (E) numbers; $n=1-2$ mice/group, and experiments were independently performed 3 times. Error bars represent SEM. ${ }^{*}, \mathrm{P}<0.05 ;{ }^{* *}, \mathrm{P}<0.01 ;{ }^{* * *}, \mathrm{P}<0.001$ versus wild-type. $\S, \mathrm{P}<0.05 ; \S \S, \mathrm{P}<0.01 ;$; §§, $\mathrm{P}<0.001$ versus sEH ${ }^{-l-}$ and solvent.

Welcker et and Clurman, 2008), and endothelial cell-specific and inducible Fbxw7 mutant (Fbxw $\left.7^{\mathrm{iECKO}}\right)$ mice demonstrate retinal blood vessel growth impairment that is attributable to Notch activation (Izumi et al., 2012). To confirm the in vitro data suggesting that $19,20-\mathrm{DHDP}$ inhibits $\gamma$-secretase activity, the lipid was given intravitrealy to $\mathrm{Fbxw} 77^{\mathrm{iECKO}}$ mice. Also in these animals, 19,20-DHDP increased sprouting and filopodia numbers (Fig. 10), confirming the inhibition of NICD generation by the lipid. Similar effects were observed in animals that received DAPT, whereas 19,20-EDP was without effect.

\section{DISCUSSION}

The results of the present study show that the genetic deletion and inhibition of the sEH activates Notch signaling and attenuates physiological sprouting angiogenesis in the murine

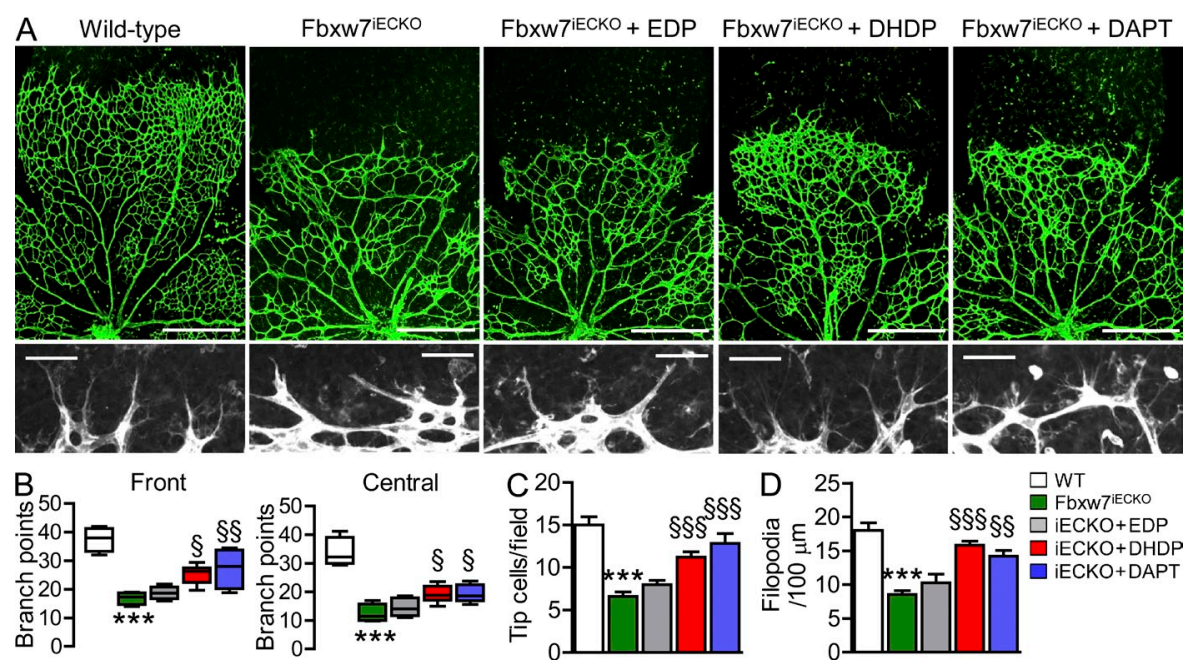

Figure 10. 19,20-DHDP and DAPT rescue retinal angiogenesis in Fbxw7 7 iECKO mice. (A) Isolectin B4 staining of the retinal whole mounts (top; bars, $500 \mu \mathrm{m}$ ) and tip cells at the angiogenic front (bottom; bars, $50 \mu \mathrm{m}$ ) in P5 retinas from wild-type (WT) mice or Fbxw $7^{\mathrm{iECKO}}$ mice $5 \mathrm{~h}$ after intravitreal injection of $0.5 \mu \mathrm{l}$ solvent, $100 \mu \mathrm{mol} /$ liter 19,20-EDP, $100 \mu \mathrm{mol} /$ liter 19,20-DHDP, or $200 \mu \mathrm{mol} /$ liter DAPT. (B-D) The graphs summarize vessel branch points (B), tip cell (C), and filopodia numbers (D). $n=1-2$ animals per group, and the experiment was independently performed 4 times. Error bars represent SEM. ${ }^{* *}, P<0.001$ versus wild-type. $\S, P<0.05 ; \S \S, P<0.01 ; \S \S \S, P<0.001$ versus Fbxw7 $7^{\text {ECKO }}$ and solvent. 
retina. Mechanistically, these effects could be attributed to the lack of the sEH product 19,20-DHDP, a fatty acid diol derived from DHA which inhibits the $\gamma$-secretase by inducing the redistribution of presenilin 1 from lipid rafts. Moreover, 19,20-DHDP, but not the parent epoxide, was able to rescue the defective angiogenesis in $\mathrm{sEH}^{-/-}$mice as well as in animals lacking the Fbxw7 ubiquitin ligase which demonstrate strong basal activity of the Notch signaling cascade.

Müller glia cells were identified as the major source of the $\mathrm{sEH}$ in the murine retina. These cells develop and maintain a close contact with both superficial vessels and deeper capillaries via their multiple end-feet (Newman and Reichenbach, 1996) and have been implicated in angiogenesis by virtue of their ability to produce angiogenic substances in response to hypoxia (Pierce et al., 1995; Stone et al., 1995; Robbins et al., 1997). However, as the Müller cell-specific deletion of VEGF-A inhibited neovascularization in a mouse model of oxygen-induced retinopathy without affecting physiological vascularization or retinal morphology (Bai et al., 2009), it was assumed that Müller cells play a greater role in proliferative retinopathy than physiological angiogenesis. In our study, the deletion of the sEH in Müller cells clearly affected endothelial cell proliferation as well as Notch signaling and tip cell filopodia formation in mice, indicating that Müller cells make a more important contribution to retinal angiogenesis than generally appreciated. Interestingly, several recent studies also support a role for VEGF-independent signaling by Müller cells in developmental angiogenesis. For example, Müller cells secrete Norrin, a retinal signaling molecule which binds to Frizzled-4 to activate canonical Wnt/ $\beta$-catenin signaling, in the absence of which the development of the superficial vessels was attenuated and deeper intraretinal capillaries were not formed (Xu et al., 2004; Ye et al., 2009; Ohlmann and Tamm, 2012). Also, the deletion of hypoxia inducible factor- $1 \alpha$ in neuroretinal cells (includes Müller cells) results in impaired vascular development characterized by decreased tip cell filopodia and reduced vessel branching (Nakamura-Ishizu et al., 2012), a phenotype very similar to that of $\mathrm{sEH}^{-/-}$mice.

The Müller cell-specific sEH knockout $\left(\mathrm{sEH}^{\Delta \mathrm{MC}}\right)$ mice were generated using Pdgfra-cre mice (Roesch et al., 2008), which may also target astrocytes. Also, because astrocytes express the sEH (Rawal et al., 2009) and retinal angiogenesis is generally thought to be largely determined by astrocytederivedVEGF (Stone et al., 1995), we also focused on this interaction. However, although vessel branching was impaired in retinas from astrocyte-specific sEH knockout (GFAP-sEH) mice, the tip cell phenotype and Notch signaling (Hes1 and Hey1 expression) were unaltered, suggesting that another sEH-expressing cell type underlies the effects observed. Our findings do not completely rule out a role for astrocyte $\mathrm{sEH}$ in retinal angiogenesis but rather indicate that another source of the sEH plays a more dominant role.

To date, the CYP-sEH axis has been linked with the promotion of angiogenesis, as the epoxides of arachidonic acid (particularly 11,12- and 14,15-EET) promote tube formation in vitro (Munzenmaier and Harder, 2000; Michaelis et al.,
2003) and can promote the vascularization of matrix material and tumors in vivo (Jiang et al., 2007). For a while, sEH inhibitors looked like highly interesting compounds for the treatment of cardiovascular disorders (Imig and Hammock, 2009), but interest was dampened by speculation that the associated increase in EET levels could induce or promote cancer progression. Certainly, tumor growth and metastasis can be increased by $\mathrm{sEH}$ inhibition in transgenic mice with high vascular EET levels, i.e., animals that overexpressed either the human CYP2C8 or human CYP2J2 specifically in Tie-2expressing cells or that were treated with high concentrations of 14,15-EET (Panigrahy et al., 2012). The latter models were somewhat artificial and focused on the products of arachidonic acid metabolism, largely ignoring the biological actions of other lipids that feed into the same CYP-sEH axis. It was partly to assess the role of the $\mathrm{sEH}$ in angiogenesis under more physiological conditions that we determined the effects of the global and induced deletion of the sEH, as well as its pharmacological inhibition in the postnatal murine retina. We found that $\mathrm{sEH}$ deletion and inhibition resulted in markedly decreased capillary branching and endothelial cell proliferation as well as reduced tip cell numbers and filopodia.

If the epoxides of arachidonic acid possess angiogenic properties, why was angiogenesis attenuated in retinas from sEH ${ }^{-/-}$mice which demonstrate higher than normal circulating and tissue levels of EETs? One logical explanation is that other lipids generated by the sequential activity of CYP epoxygenases and the sEH exert effects that dominate over, or antagonize those of, the EETs. The retinal phenotype observed could have been due to the accumulation of an antiangiogenic epoxide or the loss of a pro-angiogenic diol, even though lipid diols are generally assumed to be either inactive or markedly less active than the parent epoxides (Imig and Hammock, 2009). To identify such lipids, we used an LCMS/MS-based lipid profiling approach to screen for the lipid epoxide or diol most affected by the deletion of the $\mathrm{sEH}$ in the retina and found that 11,12-EET, 14,15-EET, and 12,13EpOME were elevated, whereas 19,20-DHDP was attenuated in retinas from $\mathrm{sEH}^{-/-}$mice. These findings could be confirmed in isolated Müller cells. Interestingly, DHA levels are known to be higher than those of arachidonic acid in the retina (Arterburn et al., 2006), and we detected higher levels of the DHA-derived lipids 19,20-EDP and 19,20-DHDP than the epoxides and diols of arachidonic acid in retinas from 5-d-old mice.

Which of the lipids affected by the deletion of the sEH could contribute to the development of the retinal phenotype in $\mathrm{sEH}^{-/-}$mice? A significant delay in the radial extension of the vascular plexus, coupled with reduced endothelial cell proliferation as well as with fewer tip cells and filopodia, are indicative of Notch signaling activation (Hellström et al., 2007; Tammela et al., 2008). Therefore, we assessed the ability of all four candidate lipids to influence Dll4-stimulated Notch activity and the generation of the NICD. However, the sEH product 19,20,-DHDP and not the sEH substrates 19,20EDP, 11,12-EET, 14,15-EET, or 12,13-EpOME attenuated 
NICD levels. Two distinct cleavage steps are required to generate the NICD; the first is dependent on ADAM proteases and the second on the activity of the $\gamma$-secretase (Kopan and Ilagan, 2009). To determine which of these proteases could be targeted by 19,20-DHDP, we assessed its ability to influence the Dll4-induced generation of the NICD from a so-called Notch $\Delta \mathrm{E}$ that possesses only the $\gamma$-secretase cleavage site $(\mathrm{He}$ et al., 2010). The finding that 19,20-DHDP also affected NICD generation in this model indicated that its molecular target was the $\gamma$-secretase. To confirm this in vivo, we assessed the consequences of the intravitreal application of 19,20-EPD or 19,20-DHDP to 5-d-old mice with hyper-activated endothelial cell Notch signaling, i.e., animals lacking the E3 ubiquitin ligase involved in the ubiquitination and degradation of the NICD (Izumi et al., 2012). In the latter Fbxw $7^{\text {iECKO }}$ animals, which demonstrate markedly impaired retinal blood vessel growth impairment that is attributable to Notch activation (Izumi et al., 2012), 19,20-DHDP increased vessel branching as well as tip cell and filopodia numbers. The $\gamma$-secretase inhibitor DAPT elicited similar effects, whereas 19,20-EDP was ineffective.

Fatty acid epoxides such as the EETs are thought to act via a specific membrane receptor or the activation of peroxisome proliferator-activated receptors (Spector and Norris, 2007; Pfister et al., 2010). How can fatty acid diols exert biological effects that could lead to the inhibition of the $\gamma$-secretase? A cell surface receptor may not be essential, as polyunsaturated fatty acids can incorporate into membrane phospholipids and potentially influence cell signaling and biological responses by modulating the lipid microenvironment therein (Kitson et al., 2012). Certainly, the fish oils EPA and DHA are readily incorporated into phospholipids and the resulting polyunsaturated phospholipids are able to infiltrate lipid rafts as well as form non-raft domains (Williams et al., 2012). DHA, from which 19,20-DHDP is derived, is particularly interesting in this respect as it tends to incorporate more readily into lipid rafts than EPA (Williams et al., 2012). Changes in the lipid composition of the plasma membrane can have marked consequences of the formation and stability of the $\gamma$-secretase complex (Vetrivel et al., 2004; Vetrivel and Thinakaran, 2010). We found that 19,20-DHDP, but not the corresponding epoxide, altered cholesterol distribution in cellular membranes and displaced presenilin 1 from lipid rafts, where the processing of substrate proteins preferentially occurs, to non-raft fractions, thus disrupting the $\gamma$-secretase complex. Little is known about the incorporation of DHA-derived epoxides or diols into phospholipids, but this is highly likely given that the epoxides of arachidonic acid (the EETs) can be esterified to phosphatidylcholine, phosphatidylethanolamine, and phosphatidylinositols (Capdevila et al., 2000). This is not the first time a link between DHA and the $\gamma$-secretase has been reported, and although DHA increased $\gamma$-secretase activity in vascular smooth muscle cells (Delbosc et al., 2008), it was found to redistribute cholesterol out of lipid rafts (Wassall and Stillwell, 2008, 2009), thereby decreasing $\gamma$-secretase activity in a neuroblastoma cell line (Grimm et al., 2011). Our results agree with the latter study. Moreover, given that fatty acids such as DHA are rapidly metabolized by CYP and sEH enzymes and that the DHA epoxide 19,20-EDP had no effect on the $\gamma$-secretase, it is possible that the DHA diol 19,20DHDP and the activity of the sEH may underlie the previously reported changes in lipid raft composition and biological responses rather than DHA on its own.

These studies highlight the fact that consequences of $\mathrm{sEH}$ inhibition in vivo cannot be solely attributed to the accumulation of the epoxides or arachidonic acid. In fact, more and more evidence is being accumulated to demonstrate that other lipid products (epoxides and diols) of the CYP-sEH axis can affect different steps in vessel development and maturation. For example, the sEH products 12,13-DiHOME (generated from the linoleic acid epoxide 12,13-EpOME), and to a lesser extent 11,12-DHET (generated from 11,12EET), attenuate angiogenesis and vascular repair via the activation of the canonical Wnt pathway (Frömel et al., 2012). Moreover, the combination of 19,20-EDP with an sEH inhibitor was reported to inhibit primary tumor growth and metastasis by preventing the VEGF-induced phosphorylation of VEGFR2 (Zhang et al., 2013). However, why the latter lipid failed to affect retinal angiogenesis is unclear at the moment but fits with our finding that the phenotype observed in the $\mathrm{sEH}^{-/-}$mice was independent of VEGF signaling. Our study also highlights the role of the neuroretina and particularly the sEH in Müller cells in the regulation of retinal angiogenesis. It will be interesting to determine whether or not this mechanism can be exploited and whether the pathological retinal angiogenesis associated with Müller cell activation (Coorey et al., 2012), such as that observed in oxygen-induced retinopathy in preterm infants, can be linked to altered lipid signaling and modulated by sEH inhibition.

\section{MATERIALS AND METHODS}

Materials. The sEH inhibitor $t$-AUCB was provided by B. Hammock (University of California, Davis, Davis, CA). The proteasomal inhibitor MG-132 was obtained from EMD Millipore. Mouse and human Dl14 protein were obtained from R\&D Systems. DAPT, tamoxifen, and all other chemicals were purchased from either Sigma-Aldrich or Merck and Roth.

Animals. C57BL/ 6 mice (6-8 wk old) were purchased from Charles River. sEH ${ }^{-/-}$mice (Sinal et al., 2000) were provided by F. Gonzalez (National Institutes of Health, Bethesda, MD) and cross-bred for $\sim 20$ generations onto the C57BL/6 background in the animal house facility at Frankfurt University. Inducible and endothelial cell-specific Fbxw $7^{\mathrm{iECKO}}$ mutant mice, generated as described previously (Izumi et al., 2012), were treated with tamoxifen $(1 \mathrm{mg} / \mathrm{ml}$ i.p., $2 \%$ ethanol in sunflower oil, $50 \mu \mathrm{l}$ ) once a day from days $1-4$.

Floxed $\mathrm{sEH}\left(\mathrm{sEH}^{\mathrm{f} / \mathrm{fl}}\right)$ mice (Taconic) were generated using C57BL/6 embryonic stem cells for gene targeting. Positive selection cassettes flanked by FRT/F3 sites were deleted by crossing with a ubiquitously expressing FLP1 recombinase strain (Taconic). These animals were cross-bred with animals expressing Cre under the control of the GFAP promoter (FVB-TgGFAP-cre25Mes [Zhuo et al., 2001] backcrossed in the C57BL/ 6 background) to generate mice lacking $\mathrm{sEH}$ in astrocytes. Inducible $\mathrm{sEH}$ knockout mice (iCreER-sEH) were generated by breeding $\mathrm{sEH}^{\mathrm{f} / \mathrm{fl}}$ mice with the RosaCreER-T2 strain (Indra et al., 1999; cross-bred to C57BL/6) and Müller cellspecific sEH-deficient mice $\left(\mathrm{sEH}^{\Delta \mathrm{MC}}\right)$ were generated by crossing the $\mathrm{sEH} \mathrm{H}^{\mathrm{A} / \mathrm{H}}$ mice with C57BL/6-TgPdgfra-cre1Clc/J mice (Roesch et al., 2008; The Jackson Laboratory). 
Mice were housed in conditions that conform to the Guide for the Care and Use of Laboratory Animals published by the U.S. National Institutes of Health (publication no. 85-23). All experiments were approved by the governmental authorities (Regierungspräsidium Darmstadt: F28/06, F28/23, and F28/38; Münster: 84-02.04.2011.A257). Age-, gender-, and strainmatched animals (usually littermates) were used throughout.

sEH inhibition and postnatal deletion studies. To inhibit epoxide hydrolase activity, C57BL/6 pups received $t$-AUCB $(2 \mathrm{mg} / \mathrm{kg}$ i.p., twice per day) from days $1-4$. To postnatally delete the $s E H$, iCreER-sEH transgenic mice were treated with tamoxifen $(1 \mathrm{mg} / \mathrm{ml}$ i.p., $2 \%$ ethanol in sunflower oil, $50 \mu \mathrm{l})$ once a day from days 1-4 as previously described (Benedito et al., 2009). On day 5 , retinas were isolated for Western blotting and immunohistochemistry.

Intravitreal injection. Mice were anesthetized with $2 \%$ isoflurane. A drop of $0.5 \%$ proparacaine was administered as a topical local anesthesia. A fine glass micropipette connected to a $10 \mu \mathrm{l}$ Hamilton glass syringe was inserted through the incision in the cornea and slid between the iris and the lens into the posterior chamber of the eye. Each eye received $0.5 \mu$ 19,20-EDP, $100 \mu \mathrm{mol} /$ liter $19,20-\mathrm{DHDP}$, or $200 \mu \mathrm{mol} /$ liter DAPT or $0.5 \mu \mathrm{l}$ of solvent (1\% DMSO in PBS) as control. Injections were administered slowly over approximately one minute and monitored with a stereo microscope.

Endothelial cell proliferation in vivo. Proliferating endothelial cells in P5 retinas were labeled by administering $\operatorname{BrdU}(50 \mathrm{mg} / \mathrm{kg}$ i.p.; BD) $4 \mathrm{~h}$ before sacrifice. After Isolectin B4 staining, retinas were post-fixed for $30 \mathrm{~min}$ in $4 \%$ paraformaldehyde (PFA), washed three times with PBS, incubated for $1 \mathrm{~h}$ in $1 \mathrm{M} \mathrm{HCl}$, washed five times in PBS, blocked, and incubated overnight with anti-BrdU antibody (1:50; BD). Secondary detection was performed with Alexa Fluor-coupled secondary antibodies.

Retina preparation and analysis. Retinas for whole-mount immunohistochemistry were fixed in 4\% PFA for $2 \mathrm{~h}$ at room temperature, or overnight at $4^{\circ} \mathrm{C}$. After fixation, retinas were blocked and permeabilized in $1 \% \mathrm{BSA}$ and $0.5 \%$ Triton $\mathrm{X}-100$ overnight at $4^{\circ} \mathrm{C}$. Then retinas were washed three times in Pblec buffer $\left(0.5 \%\right.$ Triton X-100, $1 \mathrm{mM} \mathrm{CaCl}_{2}, 1 \mathrm{mM} \mathrm{MgCl}$, and $1 \mathrm{mM}$ $\mathrm{MnCl}_{2}$ in PBS, $\mathrm{pH}$ 6.8) and incubated overnight in Pblec containing Fitclabeled Isolectin B4 (1:100; Sigma-Aldrich). The following primary antibodies were diluted in 1\% BSA and $0.5 \%$ Triton X-100 and incubated overnight: sEH (1:250; provided by M. Arand, Institute of Pharmacology and Toxicology, Uinversity of Zurich, Zurich, Switzerland), GFAP (1:500; DAKO; or 1:1,000; EMD Millipore), NG-2 (1:1,000; EMD Millipore), AQP-4 (1:500; Santa Cruz Biotechnology, Inc.), GS (1:1,000; EMD Millipore), and vimentin (1:500; Nococastra). For secondary detection, Alexa Fluor-coupled secondary antibodies (1:200) were used. Cell nuclei were visualized with DAPI (1:200; Molecular Probes). After antibody staining, retinas were post-fixed in 4\% PFA for 15 min before flat-mounting in mounting medium (Dako). $10-\mu \mathrm{m}$ cryosections were cut after retinas were embedded within Tissue-Tek OCT Compound (Sakura). All quantification was done with high-resolution images taken using a meta laser scanning confocal microscope (LSM-510; Carl Zeiss) as previously described (Kovacevic et al., 2012).

LC-MS/MS lipid profiles. Samples were extracted twice into ethyl acetate, evaporated under nitrogen, and resuspended in methanol/water (vol. 1:2). The eicosanoid profiles generated were determined with a mass spectrometer (API4000; AB Sciex) operating in multiple reaction monitoring (MRM) mode as previously described (Michaelis et al., 2005; Frömel et al., 2012). Chromatography was performed on a Gemini C18 column (150 mm length, $2 \mathrm{~mm}$ inner diameter; particle size, $5 \mu \mathrm{m}$; Phenomenex). All fatty acid epoxides, diols, and deuterated analogues were obtained from Cayman Europe.

Müller cell culture. Müller cells were isolated from 8-12-d-old mice, as previously described (Hicks and Courtois, 1990), and cultured in DMEM/ F12 containing 10\% FCS (Biochrom), $100 \mathrm{U} / \mathrm{ml}$ penicillin, and $100 \mu \mathrm{g} / \mathrm{ml}$ streptomycin. After $6 \mathrm{~d}$, the cultures were rinsed free of nonadherent tissue, and culture medium was replenished every 3-4 d. The purity of the Müller cell cultures was characterized after each passage by testing for the expression of vimentin, AQP-4, GS, and CRALBP (Bunt-Milam and Saari, 1983). Müller cell CM was generated by culturing confluent wild-type or $\mathrm{sEH}^{-/-}$ Müller cells for $48 \mathrm{~h}$.

Adenovirus generation and Müller cell transduction. The human sEH (Ephx2) cDNA sequence, with a C-terminal Myc/His tag, was excised via NotI-PmeI from $p c D N A 3.1 \mathrm{myc} / \mathrm{His}$ as previously described (BarbosaSicard et al., 2009) and cloned into the NotI-EoRV site of the cloning plasmid pAdTrackCMV.The recombination into the adenoviral transfer plasmid and the generation of the viruses was performed as previously described (Luo et al., 2007). For the $s E H$ rescue experiments, $\mathrm{sEH}^{-/-}$Müller cells were infected with sEH adenovirus for $6 \mathrm{~h}$ and then washed four times with Hank's solution. Experiments were performed after an additional $48 \mathrm{~h}$ and sEH expression was confirmed by immunoblotting.

Müller cell and endothelial cell co-culture. $1 \times 10^{6}$ endothelial cells isolated as previously described (Fleming et al., 2005) were seeded on 6-well plates coated with fibronectin. After $4 \mathrm{~h}$, the nonadherent cells were removed and the medium was replaced with $1.1 \mathrm{ml}$ DMEM/F12 containing $10 \%$ FCS. Then Transwell inserts (Millipore) were added to the wells and seeded with $6 \times 10^{5}$ Müller cells. After $8 \mathrm{~h}$, the insert was removed and RNA was extracted from the endothelial cells.

Müller cell CM on endothelial cell proliferation. $5 \times 10^{4}$ endothelial cells were seeded in 24-well plates and stimulated with M-CM from wild-type or $\mathrm{sEH}^{-/-}$Müller cells (mixed with endothelial cell growth medium at 1:1 ratio), or solvent (DMEM/F12). Mouse VEGF at a final concentration of $50 \mathrm{ng} / \mathrm{ml}$ was used as a positive control.Viable cells were counted (CASY; Roche) after 24,48 , and $72 \mathrm{~h}$ of stimulation. For the BrdU incorporation, endothelial cells were seeded in 96-well plates $\left(1 \times 10^{4}\right.$ cells/well $)$ and stimulated with the same condition as described above for $48 \mathrm{~h}$. BrdU was added to cells $4 \mathrm{~h}$ before the end of stimulation and then BrdU incorporation was assessed using BrdU ELISA kit (Roche) according to the manufacturer's instructions.

Retinal endothelial cell isolation. Retinas were isolated from P5 mice. After digestion with $0.1 \%$ trypsin (Worthington Biochemical Corporation) and $70 \mathrm{U} / \mathrm{ml}$ collagenase type I (Biochrom) in DMEM/F12 medium at $37^{\circ} \mathrm{C}$ for $30 \mathrm{~min}$, retinal endothelial cells were isolated with anti-mouse CD 31 antibody based on magnetic bead separation similar to that described above. CD-31-positive cells were used for gene expression analysis.

RT-qPCR. Total RNA from retinas or cultured primary cells was extracted using an RNeasy kit (QIAGEN), and equal amounts $(1 \mu \mathrm{g})$ of total RNA was reverse transcribed (Superscript III; Invitrogen). Gene expression levels were detected using SYBR Green (Absolute QPCR SYBR Green Mix; Thermo Fisher Scientific). The TaqMan probe used for the detection of the D114 RNA was from Applied Biosystems. The relative expression levels of the different genes studied was calculated using the $2^{-\Delta \Delta \mathrm{Ct}}$ method with the $18 \mathrm{~S}$ RNA as a reference. The primer sequences used were as follows: $18 \mathrm{~S}$ forward, 5'-CTTTGGTCGCTCGCTCCTC-3' , reverse, 5' -CTGACCGGGTTGGTTTTGAT-3'; Dll1 forward, 5'-CATCCGATACCCAGGTTGTC-3', reverse, 5'-ACGGCTTATGGTGAGTACAG-3'; Jagged1 forward, 5'-TCTCTGACCCCTGCCATAAC-3', reverse, 5' -TTGAATCCATTCACCAGATCC-3'; Notch1 forward, 5'-CCTCAGATGGTGCTCTGATG-3', reverse, 5'-CTCAGGTCAGGGAGAACTAC-3', Hes1, forward, 5'-GAGGCGAAGGGCAAGAATAAA-3', reverse, 5'-GTGGACAGGAAGCGGGTCA-3'; Hey1 forward, 5'-TGAGCTGAGAAGGCTGGTAC-3', reverse, 5'-ACCCCAAACTCCGATAGTC-3'; and VEGF forward, 5'-GCACTGGACCCTGGCTTTACTGCTGTA-3', and reverse, 5'-GAACTTGATCACTTCATGGGACTTCTGCTC-3'.

D114-induced NICD production. Endothelial cells were seeded onto 6-well plates coated with or without $500 \mathrm{ng} / \mathrm{ml}$ recombinant mouse Dll4 protein (R\&D Systems) in $0.1 \%$ BSA/PBS for $1 \mathrm{~h}$ at room temperature. 
Experiments were performed in the presence of solvent, $10 \mu \mathrm{mol} / \mathrm{liter}$ 19,20-EDP/DHDP, $10 \mu \mathrm{mol} /$ liter 11,12-EET/DHET, $10 \mu \mathrm{mol} /$ liter 14,15EET/DHET, $3 \mu \mathrm{mol} /$ liter 12,13-EpOME/DiHOME, 20 mol/liter DAPT, or $10 \mu \mathrm{mol} /$ liter MG 132. After an additional $4 \mathrm{~h}$, cells were washed three times with PBS and lysed in a Triton X-100-containing buffer. Intracellular domain of Notch (NICD) levels were assessed by Western blotting with an S3 ( $\gamma$-secretase) cleavage-specific antibody Val1744 (Cell Signaling Technology). For the nuclear translocation of NICD, cells were fixed with $4 \%$ PFA for $15 \mathrm{~min}$ at room temperature, followed by NICD and DAPI immunostaining. Co-localization of NICD with DAPI was quantified with Image J software (National Institutes of Health).

$\boldsymbol{\gamma}$-Secretase assay. HEK 293 cells were seeded in $10 \mathrm{~cm}$ culture dishes and transfected with $6 \mu \mathrm{g}$ Notch $\Delta \mathrm{E}$ construct (provided by P. Greengard, Rockefeller University, New York, NY). Cells were then incubated with solvent,

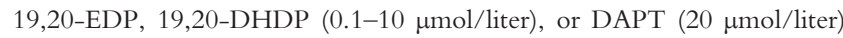
for $24 \mathrm{~h}$. The $\gamma$-secretase-dependent generation of NICD was detected as described above.

Lipid rafts. HEK293 cells were incubated with solvent (0.1\% DMSO), $10 \mu \mathrm{mol} /$ liter 19,20-EDP, $10 \mu \mathrm{mol} /$ liter 19,20-DHDP, or $20 \mu \mathrm{mol} / \mathrm{liter}$ DAPT in serum-free medium containing $10 \mu \mathrm{mol} /$ liter of the $s E H$ inhibitor $t$-AUCB for $2 \mathrm{~h}$ at $37^{\circ} \mathrm{C}$. Cells were then washed twice with ice-cold PBS, harvested by scraping, recovered by centrifugation ( $300 \mathrm{~g}$ for $4 \mathrm{~min}$ ), and resuspended in $2 \mathrm{ml} \mathrm{MBS}$ buffer (containing 1\% CHAPSO in $25 \mathrm{mM}$ MES, pH 6.5, $150 \mu \mathrm{mol} /$ liter $\mathrm{NaCl}$ supplemented with a protease inhibitor mix, and $1 \mu \mathrm{mol} /$ liter phenylmethylsulfonyl fluoride), and homogenized by using a glass homogenizer. Lipid rafts were isolated as previously described (Vetrivel et al., 2004). In brief, after $30 \mathrm{~min}$ at $4^{\circ} \mathrm{C}$, equal amounts of protein were adjusted to a final sucrose concentration of $45 \%$ (final volume, $4 \mathrm{ml}$ ) and transferred to $12 \mathrm{ml}$ ultracentrifuge tubes. A discontinuous sucrose gradient was then formed by sequentially overlaying $4 \mathrm{ml}$ of $35 \%$ and $4 \mathrm{ml}$ of $5 \%$ sucrose. Samples were subjected to ultracentrifugation $\left(35,000 \mathrm{rpm}, 4^{\circ} \mathrm{C}\right.$ for $20 \mathrm{~h}$ ) using a rotor (SW 41; Beckman). After centrifugation, twelve $1 \mathrm{ml}$ fractions were collected using a capillary tube connected to a peristaltic pump, and equal volumes of each faction were analyzed by SDS-PAGE using antibodies against flotillin 1 (BD) and presenilin 1 (Santa Cruz Biotechnology, Inc.). Cholesterol levels in the different fractions were determined using the Amplex Red cholesterol assay (Invitrogen) according to the manufacturer's instructions.

Statistical analysis. Data are expressed as mean \pm SEM, and statistical evaluation was performed using Student's $t$ test for unpaired data or one-way ANOVA, followed by a Bonferroni's $t$ test where appropriate. Values of $\mathrm{P}<0.05$ were considered statistically significant.

The authors are indebted to Isabel Winter and Katharina Engel-Herbig for expert technical assistance.

This work was supported by the Deutsche Forschungsgemeinschaft (SFB-TR 23/A6, GRK 880 and Exzellenzcluster 147 "Cardio-Pulmonary Systems"). J. Hu was supported by a research scholarship from China Scholarship Council (CSC).

The authors declare no competing financial interests.

Submitted: 16 July 2013

Accepted: 6 January 2014

\section{REFERENCES}

Arterburn, L.M., E.B. Hall, and H. Oken. 2006. Distribution, interconversion, and dose response of $\mathrm{n}-3$ fatty acids in humans. Am. J. Clin. Nutr. 83:1467S-1476S.

Bai, Y., J.X. Ma, J. Guo, J. Wang, M. Zhu, Y. Chen, and Y.Z. Le. 2009. Müller cell-derived VEGF is a significant contributor to retinal neovascularization. J. Pathol. 219:446-454. http://dx.doi.org/10.1002/path.2611

Barbosa-Sicard, E., T. Frömel, B. Keserü, R.P. Brandes, C. Morisseau, B.D. Hammock, T. Braun, M. Krüger, and I. Fleming. 2009. Inhibition of the soluble epoxide hydrolase by tyrosine nitration. J. Biol. Chem. 284:28156-28163. http://dx.doi.org/10.1074/jbc.M109.054759
Benedito, R., C. Roca, I. Sörensen, S. Adams, A. Gossler, M. Fruttiger, and R.H. Adams. 2009. The notch ligands D114 and Jagged1 have opposing effects on angiogenesis. Cell. 137:1124-1135. http://dx.doi.org/10 $.1016 /$ j.cell.2009.03.025

Boulton, M.E., J. Cai, and M.B. Grant. 2008. $\gamma$-Secretase: a multifaceted regulator of angiogenesis. J. Cell. Mol. Med. 12:781-795. http://dx.doi .org/10.1111/j.1582-4934.2008.00274.x

Bunt-Milam, A.H., and J.C. Saari. 1983. Immunocytochemical localization of two retinoid-binding proteins in vertebrate retina. J. Cell Biol. 97:703-712. http://dx.doi.org/10.1083/jcb.97.3.703

Capdevila, J.H., J.R. Falck, and R.C. Harris. 2000. Cytochrome P450 and arachidonic acid bioactivation. Molecular and functional properties of the arachidonate monooxygenase. J. Lipid Res. 41:163-181.

Coorey, N.J., W. Shen, S.H. Chung, L. Zhu, and M.C. Gillies. 2012. The role of glia in retinal vascular disease. Clin. Exp. Optom. 95:266-281. http://dx.doi.org/10.1111/j.1444-0938.2012.00741.x

Cronin, A., S. Mowbray, H. Dürk, S. Homburg, I. Fleming, B. Fisslthaler, F. Oesch, and M. Arand. 2003. The N-terminal domain of mammalian soluble epoxide hydrolase is a phosphatase. Proc. Natl. Acad. Sci. USA. 100:1552-1557. http://dx.doi.org/10.1073/pnas.0437829100

Dawson, D.W., O.V. Volpert, P. Gillis, S.E. Crawford, H.J. Xu, W. Benedict, and N.P. Bouck. 1999. Pigment epithelium-derived factor: a potent inhibitor of angiogenesis. Science. 285:245-248. http://dx.doi .org/10.1126/science.285.5425.245

Delbosc, S., M. Glorian, A.S. Le Port, G. Béréziat, M. Andréani, and I. Limon. 2008. The benefit of docosahexanoic acid on the migration of vascular smooth muscle cells is partially dependent on Notch regulation of MMP -2/-9. Am. J. Pathol. 172:1430-1440. http://dx.doi.org/10.2353/ajpath .2008 .070951

Fleming, I. 2011. The cytochrome P450 pathway in angiogenesis and endothelial cell biology. Cancer Metastasis Rev. 30:541-555. http://dx.doi.org/ 10.1007/s10555-011-9302-3

Fleming, I., B. Fisslthaler, M. Dixit, and R. Busse. 2005. Role of PECAM-1 in the shear-stress-induced activation of Akt and the endothelial nitric oxide synthase (eNOS) in endothelial cells. J. Cell Sci. 118:4103-4111. http://dx.doi.org/10.1242/jcs.02541

Frömel, T., B. Jungblut, J. Hu, C. Trouvain, E. Barbosa-Sicard, R. Popp, S. Liebner, S. Dimmeler, B.D. Hammock, and I. Fleming. 2012. Soluble epoxide hydrolase regulates hematopoietic progenitor cell function via generation of fatty acid diols. Proc. Natl. Acad. Sci. USA. 109:999510000. http://dx.doi.org/10.1073/pnas.1206493109

Gerhardt, H., M. Golding, M. Fruttiger, C. Ruhrberg, A. Lundkvist, A. Abramsson, M. Jeltsch, C. Mitchell, K. Alitalo, D. Shima, and C. Betsholtz. 2003. VEGF guides angiogenic sprouting utilizing endothelial tip cell filopodia. J. Cell Biol. 161:1163-1177. http://dx.doi.org/10 $.1083 /$ jcb. 200302047

Grimm, M.O.W., J. Kuchenbecker, S. Grösgen, V.K. Burg, B. Hundsdörfer, T.L. Rothhaar, P. Friess, M.C. de Wilde, L.M. Broersen, B. Penke, et al. 2011. Docosahexaenoic acid reduces amyloid $\beta$ production via multiple pleiotropic mechanisms. J. Biol. Chem. 286:14028-14039. http://dx.doi.org/10.1074/jbc.M110.182329

He, G., W. Luo, P. Li, C. Remmers, W.J. Netzer, J. Hendrick, K. Bettayeb, M. Flajolet, F. Gorelick, L.P. Wennogle, and P. Greengard. 2010. Gamma-secretase activating protein is a therapeutic target for Alzheimer's disease. Nature. 467:95-98. http://dx.doi.org/10.1038/ nature 09325

Hellström, M., L.K. Phng, J.J. Hofmann, E. Wallgard, L. Coultas, P. Lindblom, J. Alva, A.K. Nilsson, L. Karlsson, N. Gaiano, et al. 2007. D114 signalling through Notch1 regulates formation of tip cells during angiogenesis. Nature. 445:776-780. http://dx.doi.org/10.1038/nature05571

Hicks, D., and Y. Courtois. 1990. The growth and behaviour of rat retinal Müller cells in vitro. 1. An improved method for isolation and culture. Exp. Eye Res. 51:119-129. http://dx.doi.org/10.1016/0014-4835(90) 90063-Z

Hur, J.Y., H. Welander, H. Behbahani, M. Aoki, J. Frånberg, B. Winblad, S. Frykman, and L.O. Tjernberg. 2008. Active $\gamma$-secretase is localized to detergent-resistant membranes in human brain. FEBS J. 275:11741187. http://dx.doi.org/10.1111/j.1742-4658.2008.06278.x 
Hwang, S.H., H.J. Tsai, J.Y. Liu, C. Morisseau, and B.D. Hammock. 2007. Orally bioavailable potent soluble epoxide hydrolase inhibitors. J. Med. Chem. 50:3825-3840. http://dx.doi.org/10.1021/jm070270t

Imig, J.D. 2012. Epoxides and soluble epoxide hydrolase in cardiovascular physiology. Physiol. Rev. 92:101-130. http://dx.doi.org/10.1152/ physrev.00021.2011

Imig, J.D., and B.D. Hammock. 2009. Soluble epoxide hydrolase as a therapeutic target for cardiovascular diseases. Nat. Rev. Drug Discov. 8:794805. http://dx.doi.org/10.1038/nrd2875

Indra, A.K., X. Warot, J. Brocard, J.M. Bornert, J.H. Xiao, P. Chambon, and D. Metzger. 1999. Temporally-controlled site-specific mutagenesis in the basal layer of the epidermis: comparison of the recombinase activity of the tamoxifen-inducible Cre-ER(T) and Cre-ER(T2) recombinases. Nucleic Acids Res. 27:4324-4327. http://dx.doi.org/10.1093/nar/27.22.4324

Izumi, N., C. Helker, M. Ehling, A. Behrens, W. Herzog, and R.H. Adams. 2012. Fbxw7 controls angiogenesis by regulating endothelial Notch activity. PLoS ONE. 7:e41116. http://dx.doi.org/10.1371/journal.pone .0041116

Jiang, J.G., Y.G. Ning, C. Chen, D. Ma, Z.J. Liu, S. Yang, J. Zhou, X. Xiao, X.A. Zhang, M.L. Edin, et al. 2007. Cytochrome p450 epoxygenase promotes human cancer metastasis. Cancer Res. 67:6665-6674. http://dx.doi.org/10.1158/0008-5472.CAN-06-3643

Kitson, A.P., K.D. Stark, and R.E. Duncan. 2012. Enzymes in brain phospholipid docosahexaenoic acid accretion: a PL-ethora of potential PLayers. Prostaglandins Leukot. Essent. Fatty Acids. 87:1-10. http://dx.doi .org/10.1016/j.plefa.2012.06.001

Konkel, A., and W.H. Schunck. 2011. Role of cytochrome P450 enzymes in the bioactivation of polyunsaturated fatty acids. Biochim. Biophys. Acta. 1814:210-222. http://dx.doi.org/10.1016/j.bbapap.2010.09.009

Kopan, R., and M.X. Ilagan. 2009. The canonical Notch signaling pathway: unfolding the activation mechanism. Cell. 137:216-233. http://dx.doi .org/10.1016/j.cell.2009.03.045

Kovacevic, I., J. Hu, A. Siehoff-Icking, N. Opitz, A. Griffin, A.C. Perkins, A.L. Munn, W. Müller-Esterl, R. Popp, I. Fleming, et al. 2012. The F-BAR protein NOSTRIN participates in FGF signal transduction and vascular development. EMBO J. 31:3309-3322. http://dx.doi.org/10.1038/ emboj.2012.176

Luo, J., Z.L. Deng, X. Luo, N. Tang, W.X. Song, J. Chen, K.A. Sharff, H.H. Luu, R.C. Haydon, K.W. Kinzler, et al. 2007. A protocol for rapid generation of recombinant adenoviruses using the AdEasy system. Nat. Protoc. 2:1236-1247. http://dx.doi.org/10.1038/nprot.2007.135

Medhora, M., J. Daniels, K. Mundey, B. Fisslthaler, R. Busse, E.R. Jacobs, and D.R. Harder. 2003. Epoxygenase-driven angiogenesis in human lung microvascular endothelial cells. Am. J. Physiol. Heart Circ. Physiol. 284:H215-H224.

Michaelis, U.R., B. Fisslthaler, M. Medhora, D. Harder, I. Fleming, and R. Busse. 2003. Cytochrome P450 2C9-derived epoxyeicosatrienoic acids induce angiogenesis via cross-talk with the epidermal growth factor receptor (EGFR). FASEB J. 17:770-772.

Michaelis, U.R., B. Fisslthaler, E. Barbosa-Sicard, J.R. Falck, I. Fleming, and R. Busse. 2005. Cytochrome P450 epoxygenases 2C8 and 2C9 are implicated in hypoxia-induced endothelial cell migration and angiogenesis. J. Cell Sci. 118:5489-5498. http://dx.doi.org/10.1242/ jcs. 02674

Munzenmaier, D.H., and D.R. Harder. 2000. Cerebral microvascular endothelial cell tube formation: role of astrocytic epoxyeicosatrienoic acid release. Am. J. Physiol. Heart Circ. Physiol. 278:H1163-H1167.

Nakamura-Ishizu, A., T. Kurihara, Y. Okuno, Y. Ozawa, K. Kishi, N. Goda, K. Tsubota, H. Okano, T. Suda, and Y. Kubota. 2012. The formation of an angiogenic astrocyte template is regulated by the neuroretina in a HIF-1-dependent manner. Dev. Biol. 363:106-114. http:// dx.doi.org/10.1016/j.ydbio.2011.12.027

Newman, E., and A. Reichenbach. 1996. The Müller cell: a functional element of the retina. Trends Neurosci. 19:307-312. http://dx.doi.org/10 $.1016 / 0166-2236(96) 10040-0$

Newman, J.W., C. Morisseau, T.R. Harris, and B.D. Hammock. 2003. The soluble epoxide hydrolase encoded by EPXH2 is a bifunctional enzyme with novel lipid phosphate phosphatase activity. Proc. Natl. Acad. Sci. USA. 100:1558-1563. http://dx.doi.org/10.1073/pnas.0437724100
Ohlmann, A., and E.R. Tamm. 2012. Norrin: molecular and functional properties of an angiogenic and neuroprotective growth factor. Prog. Retin. Eye Res. 31:243-257. http://dx.doi.org/10.1016/j.preteyeres .2012 .02 .002

Panigrahy, D., M.L. Edin, C.R. Lee, S. Huang, D.R. Bielenberg, C.E. Butterfield, C.M. Barnés, A. Mammoto, T. Mammoto, A. Luria, et al. 2012. Epoxyeicosanoids stimulate multiorgan metastasis and tumor dormancy escape in mice. J. Clin. Invest. 122:178-191. http://dx.doi.org/10 $.1172 / \mathrm{JCI} 58128$

Pfister, S.L., K.M. Gauthier, and W.B. Campbell. 2010. Vascular pharmacology of epoxyeicosatrienoic acids. Adv. Pharmacol. 60:27-59. http:// dx.doi.org/10.1016/B978-0-12-385061-4.00002-7

Phng, L.K., and H. Gerhardt. 2009. Angiogenesis: a team effort coordinated by notch. Dev. Cell. 16:196-208. http://dx.doi.org/10.1016/ j.devcel.2009.01.015

Pierce, E.A., R.L. Avery, E.D. Foley, L.P. Aiello, and L.E. Smith. 1995. Vascular endothelial growth factor/vascular permeability factor expression in a mouse model of retinal neovascularization. Proc. Natl. Acad. Sci. USA. 92:905-909. http://dx.doi.org/10.1073/pnas.92.3.905

Potente, M., H. Gerhardt, and P. Carmeliet. 2011. Basic and therapeutic aspects of angiogenesis. Cell. 146:873-887. http://dx.doi.org/10.1016/ j.cell.2011.08.039

Rawal, S., C. Morisseau, B.D. Hammock, and A.C. Shivachar. 2009. Differential subcellular distribution and colocalization of the microsomal and soluble epoxide hydrolases in cultured neonatal rat brain cortical astrocytes. J. Neurosci. Res. 87:218-227. http://dx.doi.org/10.1002/jnr.21827

Robbins, S.G., J.R. Conaway, B.L. Ford, K.A. Roberto, and J.S. Penn. 1997. Detection of vascular endothelial growth factor (VEGF) protein in vascular and non-vascular cells of the normal and oxygen-injured rat retina. Growth Factors. 14:229-241. http://dx.doi.org/10.3109/ 08977199709021522

Roesch, K., A.P. Jadhav, J.M. Trimarchi, M.B. Stadler, B. Roska, B.B. Sun, and C.L. Cepko. 2008. The transcriptome of retinal Müller glial cells. J. Comp. Neurol. 509:225-238. http://dx.doi.org/10.1002/ cne. 21730

Salvado, M.D., A. Alfranca, J.Z. Haeggström, and J.M. Redondo. 2012. Prostanoids in tumor angiogenesis: therapeutic intervention beyond COX-2. Trends Mol. Med. 18:233-243. http://dx.doi.org/10.1016/ j.molmed.2012.02.002

Sinal, C.J., M. Miyata, M. Tohkin, K. Nagata, J.R. Bend, and F.J. Gonzalez. 2000. Targeted disruption of soluble epoxide hydrolase reveals a role in blood pressure regulation. J. Biol. Chem. 275:40504-40510. http:// dx.doi.org/10.1074/jbc.M008106200

Spector, A.A., and A.W. Norris. 2007. Action of epoxyeicosatrienoic acids on cellular function. Am. J. Physiol. Cell Physiol. 292:C996-C1012. http://dx.doi.org/10.1152/ajpcell.00402.2006

Stone, J., and Z. Dreher. 1987. Relationship between astrocytes, ganglion cells and vasculature of the retina. J. Comp. Neurol. 255:35-49. http:// dx.doi.org/10.1002/cne. 902550104

Stone, J., A. Itin, T. Alon, J. Pe'er, H. Gnessin, T. Chan-Ling, and E. Keshet. 1995. Development of retinal vasculature is mediated by hypoxia-induced vascular endothelial growth factor (VEGF) expression by neuroglia. J. Neurosci. 15:4738-4747.

Tammela, T., G. Zarkada, E. Wallgard, A. Murtomäki, S. Suchting, M. Wirzenius, M. Waltari, M. Hellström, T. Schomber, R. Peltonen, et al. 2008. Blocking VEGFR-3 suppresses angiogenic sprouting and vascular network formation. Nature. 454:656-660.http://dx.doi.org/10.1038/ nature 07083

Tan, Y., O. Sangfelt, and C. Spruck. 2008. The Fbxw7/hCdc4 tumor suppressor in human cancer. Cancer Lett. 271:1-12. http://dx.doi.org/10 $.1016 /$ j.canlet.2008.04.036

Vetrivel, K.S., and G. Thinakaran. 2010. Membrane rafts in Alzheimer's disease beta-amyloid production. Biochim. Biophys. Acta. 1801:860-867. http://dx.doi.org/10.1016/j.bbalip.2010.03.007

Vetrivel, K.S., H. Cheng, W. Lin, T. Sakurai, T. Li, N. Nukina, P.C. Wong, H. Xu, and G. Thinakaran. 2004. Association of $\gamma$-secretase with lipid rafts in post-Golgi and endosome membranes. J. Biol. Chem. 279:44945-44954. http://dx.doi.org/10.1074/jbc.M407986200 
Wang,Y., X. Wei, X. Xiao, R. Hui, J.W. Card, M.A. Carey, D.W.Wang, and D.C. Zeldin. 2005. Arachidonic acid epoxygenase metabolites stimulate endothelial cell growth and angiogenesis via mitogen-activated protein kinase and phosphatidylinositol 3-kinase/Akt signaling pathways. J. Pharmacol. Exp. Ther. 314:522-532. http://dx.doi.org/10.1124/jpet.105.083477

Wassall, S.R., and W. Stillwell. 2008. Docosahexaenoic acid domains: the ultimate non-raft membrane domain. Chem. Phys. Lipids. 153:57-63. http://dx.doi.org/10.1016/j.chemphyslip.2008.02.010

Wassall, S.R., and W. Stillwell. 2009. Polyunsaturated fatty acid-cholesterol interactions: domain formation in membranes. Biochim. Biophys. Acta 1788:24-32. http://dx.doi.org/10.1016/j.bbamem.2008.10.011

Webler, A.C., R. Popp, T. Korff, U.R. Michaelis, C. Urbich, R. Busse, and I. Fleming. 2008. Cytochrome P450 2C9-induced angiogenesis is dependent on EphB4. Arterioscler. Thromb. Vasc. Biol. 28:1123-1129. http://dx.doi.org/10.1161/ATVBAHA.107.161190

Welcker, M., and B.E. Clurman. 2008. FBW7 ubiquitin ligase: a tumour suppressor at the crossroads of cell division, growth and differentiation. Nat. Rev. Cancer. 8:83-93. http://dx.doi.org/10.1038/nrc2290

Williams, J.A., S.E. Batten, M. Harris, B.D. Rockett, S.R. Shaikh, W Stillwell, and S.R. Wassall. 2012. Docosahexaenoic and eicosapentaenoic acids segregate differently between raft and nonraft domains. Biophys. J. 103:228-237. http://dx.doi.org/10.1016/j.bpj.2012.06.016
Xu, Q., Y. Wang, A. Dabdoub, P.M. Smallwood, J. Williams, C. Woods, M.W. Kelley, L. Jiang, W. Tasman, K. Zhang, and J. Nathans. 2004. Vascular development in the retina and inner ear: control by Norrin and Frizzled-4, a high-affinity ligand-receptor pair. Cell. 116:883-895. http://dx.doi.org/10.1016/S0092-8674(04)00216-8

Ye, X., Y. Wang, H. Cahill, M.Yu, T.C. Badea, P.M. Smallwood, N.S. Peachey, and J. Nathans. 2009. Norrin, frizzled-4, and Lrp5 signaling in endothelial cells controls a genetic program for retinal vascularization. Cell. 139:285-298. http://dx.doi.org/10.1016/j.cell.2009.07.047

Zhang, C., and D.R. Harder. 2002. Cerebral capillary endothelial cell mitogenesis and morphogenesis induced by astrocytic epoxyeicosatrienoic Acid. Stroke. 33:2957-2964. http://dx.doi.org/10.1161/01.STR $.0000037787 .07479 .9 \mathrm{~A}$

Zhang, G., D. Panigrahy, L.M. Mahakian, J.Yang, J.Y. Liu, K.S. Stephen Lee, H.I. Wettersten, A. Ulu, X. Hu, S. Tam, et al. 2013. Epoxy metabolites of docosahexaenoic acid (DHA) inhibit angiogenesis, tumor growth, and metastasis. Proc. Natl. Acad. Sci. USA. 110:6530-6535. http://dx.doi .org/10.1073/pnas.1304321110

Zhuo, L., M. Theis, I. Alvarez-Maya, M. Brenner, K. Willecke, and A. Messing. 2001. hGFAP-cre transgenic mice for manipulation of glial and neuronal function in vivo. Genesis. 31:85-94. http://dx.doi .org/10.1002/gene. 10008 